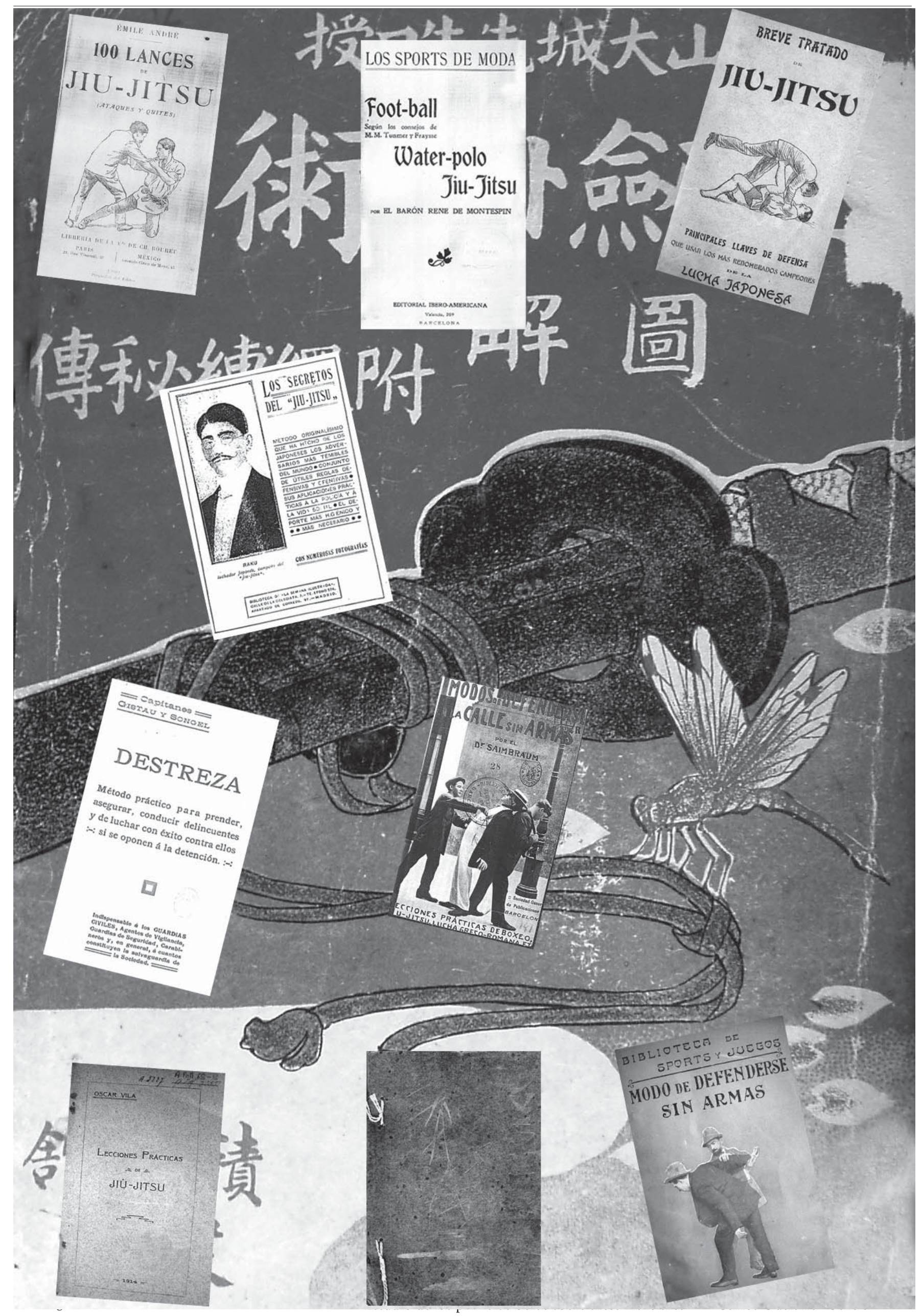




\title{
Estudio de las primeras obras sobre artes marciales escritas en español
}

\author{
Carlos Gutiérrez García
}

\begin{abstract}
Resumen
En este trabajo se analizan las primeras obras sobre artes marciales escritas en español, publicadas fundamentalmente en España durante la primera y segunda década del s. XX. A partir de este análisis, que comprende seis libros completos y secciones de tres libros más, se aprecian todo el conjunto de imágenes que caracterizaron al jujutsu -la primera de las artes marciales en difundirse en Occidente- en sus primeros tiempos lejos de Japón, consecuencia de una mirada occidental habitualmente superficial y desinformada. También puede observarse la falta de originalidad de las obras estudiadas, ya que en su gran mayoría son traducciones y/o adaptaciones de publicaciones anteriores francesas, inglesas o norteamericanas.
\end{abstract}

\section{Introducción}

El comienzo del s. XX marca un momento trascendental en la evolución de las artes marciales asiáticas. Utilizando un término actualmente de moda, durante estos años se iniciaba su proceso de "globalización", siendo el jujutsu la punta de lanza de un movimiento que no llegaría únicamente al Occidente europeo y norteamericano, sino también a muchos otros países y continentes.

Uno de los vestigios más interesantes de esta primera época de las artes marciales en Occidente lo constituyen los libros escritos sobre la materia (véanse los trabajos de Dudenbostel, 1943; Smith, 1961; Nelson, 1988; Brousse, 2000). Raros, y habitualmente difíciles de localizar y adquirir, conforman un valioso legado a través del cual vislumbrar la concepción existente sobre aquel nuevo método de combate importado de Japón.

El presente estudio analiza un número significativo de obras sobre artes marciales escritas en español durante las dos primeras décadas del s. XX. Partiendo de las referencias citadas en los catálogos de Llaverías (1910), Museo pedagógico Nacional (1915), Blanco (1927) y Palau (1935, 1948-1949), así como de los catálogos informatizados de las bibliotecas nacionales y universitarias españolas y de otros países hispanohablantes, se ha elaborado un listado de obras que han podido ser mayoritariamente localizadas y estudiadas. Únicamente en dos casos no hemos encontrado

Todas las fotografías son cortesía de Carlos Gutiérrez García. 
ejemplares de consulta. Se trata de las obras de A. Koyama y K. Minami La lucha corporal japonesa (Barcelona: s.n., [1916]) ${ }^{1}$, citada en el catálogo de Rufino Blanco, y del libro de Mitsuyo Maeda Defensa personal al alcance de todos (San Salvador: Tipografía Nacional, [1913]), citado por Urbina (2006) en su trabajo sobre los orígenes del deporte moderno en El Salvador. Obviamente, también cabe la posibilidad de que se publicasen otras obras que no estuviesen citadas en los catálogos referidos anteriormente y de las que aún no tenemos constancia.

\section{0 lances de jiu-jitsu (ataques y quites)}

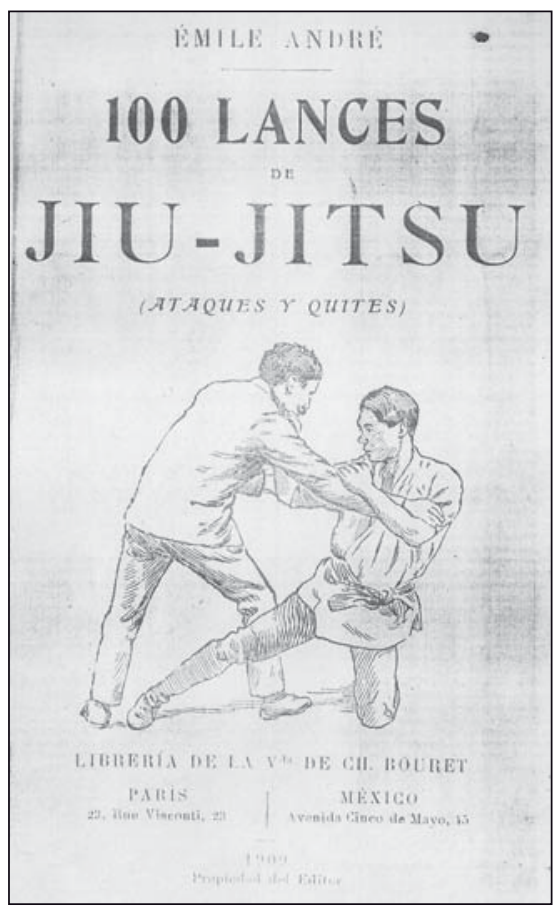

Portada del libro 100 lances de jiu-jitsu (ataques y quites).

Debajo, la ilustración original del libro de Irving Hancock The Complete Kano Jiu-Jitsu.

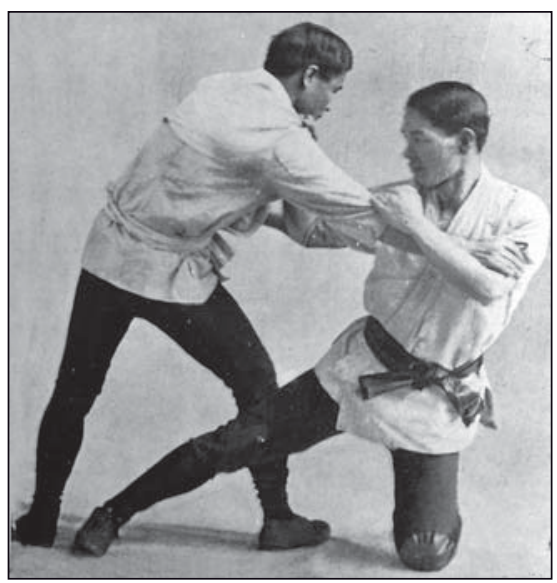

Curiosamente, el primer libro sobre artes marciales escrito en español del que tenemos noticia no se publicó en España ni en ningún país hispanohablante, sino en la parisina imprenta de la Viuda de Ch. Bouret en 1906. Se trata de la obra 100 lances de jiu-jitsu. (Ataques y quites), de Émile André (traducción de C.D.), publicada originalmente en francés también en 1906 bajo el título 100 coups de jiu-jitsu (coups et parades) ${ }^{2}$.

Émile André, un reconocido divulgador de la cultura física en la Francia de finales del s. XIX y principios del s. XX, fue además autor de numerosas obras sobre deportes de combate, dos de las cuales también se tradujeron al español (véase bibliografía). No se trataba, por tanto, de un especialista en lucha japonesa, sino de un estudioso de los métodos de combate que al igual que otros se interesó por las innovaciones técnicas que trajo el jujutsu. También supo aprovechar inteligentemente con sus obras la época de inseguridad ciudadana que vivía la capital francesa a principios del s. XX, cuando los temibles ladrones conocidos como "apaches" lograron una inusitada fama gracias a la prensa.

El libro 100 lances de jiu-jitsu consta de 137 páginas que son una fiel reproducción del original en francés, tanto en lo que se refiere a la traducción como a las ilustraciones. La edición en español añade al final del libro un breve capítulo de siete páginas que recupera algunas de las técnicas de la obra 100 Façons de se defender dans la rue sans armes. Respecto a las ilustraciones, un buen número de las mismas ya aparecen en dos de sus obras, L'art de se defender dans la rue y 100 Façons de se défendre dans la rue sans armes, ambas sin relación directa con el jujutsu. No obstante, según señala el propio autor "ya una parte considerable del método era conocida en Francia con el nombre de lucha libre" (p. VI), y por ello habría aprovechado algunos grabados de sus obras anteriores, basadas en la lucha libre.

Por el contrario, y puesto que "para los lances y quites especialmente japoneses, referentes á la parte original del jiu-jitsu, convendría tener actitudes de demostradores nipones afamados" (p. XIX), André señala que utilizó como modelo a Katsukuma Higashi, uno de los principales difusores del jujutsu en Occidente a principios del s. XX. Aquí podemos cuestionar las palabras del autor puesto que los grabados de las técnicas "especialmente japonesas" son en su gran mayoría un calco de las fotografías que ilustran The Complete Kano Jiu-Jitsu, libro realizado por el escritor norteamericano Harrie Irving Hancock y el propio Higashi y publicado en Nueva York en $1905^{3}$. La única diferencia en los grabados es que se ha dado una apariencia occidental al compañero de Higashi, tanto en el aspecto como en la vestimenta, mientras que en el original americano dicho compañero es otro japonés ataviado con el uniforme propio del jujutsu. Este cambio puede interpretarse tanto por un interés en disimular la verdadera procedencia de 
las fotografías como por el intento de enfatizar el carácter del jujutsu como método de autodefensa, ya que la apariencia de los originales es mucho más "deportiva".

En cuanto a los contenidos, la obra se estructura fundamentalmente en dos partes, una dedicada a golpeos titulada "Ataques y quites en sustitución del pugilato francés", y otra dedicada a proyecciones y controles titulada "Lances de lucha libre". Con una extensión mucho menor, un capítulo introductorio y otros dedicados a las técnicas de reanimación o kuatsu, a las mujeres y el jujutsu, y a la defensa contra armas blancas.

Como ya se ha apuntado anteriormente, André orienta su obra clara e intencionalmente hacia el aspecto utilitario del jujutsu como método de defensa. Navegando entre dos aguas, el autor reconoce la originalidad del jujutsu, si bien gran parte del método era ya conocido en Francia bajo el nombre de lucha libre, circunstancia que reitera habitualmente a lo largo de la obra. Entre las innovaciones introducidas por el jujutsu se señalan 1) Ejercicios específicos, como caídas, ejercicios de endurecimiento, de esquiva, etc., 2) Golpes con el canto exterior de la mano, con una acción mucho más localizada que aquellos ejecutados con los puños, 3) Una menor utilización de las patadas en comparación al pugilato francés (savatte), 4) Nuevas técnicas de torsión y luxación, 5) Un rico y complejo trabajo de piernas en las proyecciones, 6) Un estudio detallado de los puntos débiles del cuerpo humano, y 7) El kuatsu.

Del mismo modo, reconoce la agilidad, rapidez, flexibilidad y destreza de los luchadores japoneses, a la vez que señala que el jujutsu tiene "cierto número de lances y de paradas que sólo hombres muy hábiles por naturaleza, y muy adiestrados por la costumbre, pueden permitirse" (p. VIII). Pero también afirma que "Otros lances, otros medios de defensa están más al alcance de los simples mortales" y que "No requiere el jiu-jitsu mucho vigor físico, puesto que el método tiende, al contrario, á permitir el triunfo de la destreza y de la agilidad sobre la fuerza bruta" (p. VIII).

Respecto al kuatsu, el autor comenta el ocultismo que caracteriza a su práctica -"rodean de cierto misterio su ciencia: pretenden no poder decirlo todo, especialmente á los occidentales"- para preguntarse seguidamente si "En realidad iquedan muchos secretos por descubrir en este asunto?". Y concluir al final de la sección: "Son menester conocimientos especiales para salir airoso en el empleo del kuatsu, según los varios casos que es capaz de remediar" (pp. 108-109). Una dualidad semejante plantea en relación a las mujeres y el jujutsu, donde a la vez que se aconseja:

No os veo bien, encantadoras misses, ocupadas en endurecer el canto exterior de vuestra mano, y en hacer inextrangulables vuestros lindos cuellos. Mejor os conviene el bienhechor kuatsu. En todos los paises, la mayoría de los deportes de defensa son incompatibles con la gracia femenina (p. III).

Se afirma seguidamente:

Lo que con relativa facilidad pueden practicar es ciertos golpes con el canto de la mano, los que resultan eficaces sin exigir mucha fuerza; golpes de codo y varias torsiones de dedos, de muñecas, ó hasta de brazos, pues hay torsiones de brazos que no requieren mucho vigor. [...] Á las mujeres de este género podrían convenir varios lances del jiu-jitsu. Pero no insistamos: se pondrían á estudiarlos con ahínco, lo cual pudiera ser funesto á los puntos flacos de sus maridos (pp. | / /-1/2).

En definitiva, 100 lances de jiu-jitsu (ataques y quites) es un tratado técnico
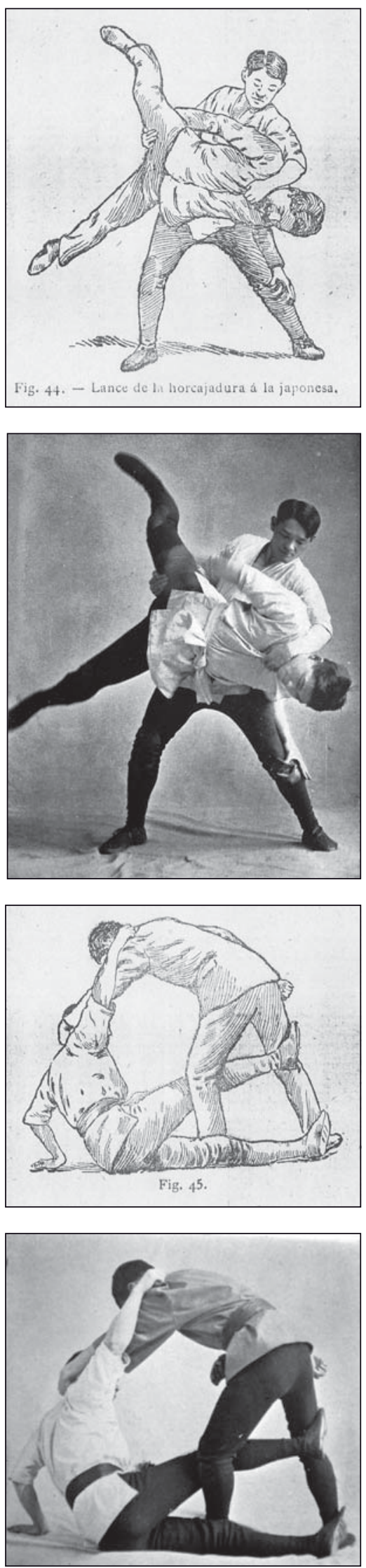

Dibujos de la obra 100 lances de jiu-jitsu (ataques y quites) y fotografías originales de The Complete Kano Jiu-jitsu. 

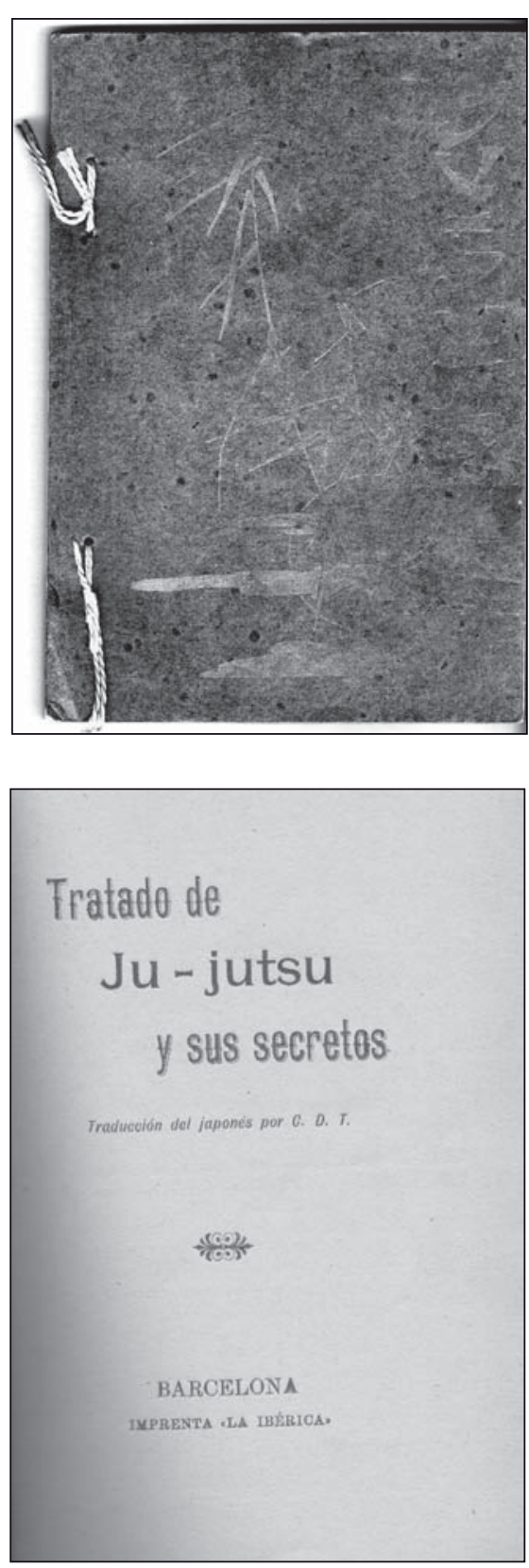

Portada contraportada del libro Tratado de Ju-jutsu y sus secretos. eminentemente divulgativo, en el que el autor mantiene un juego de equilibrio entre la originalidad / no originalidad, facilidad / dificultad, mitificación / desmitificación del jujutsu. Esto no responde únicamente al intento de André de estudiar comparativamente el jujutsu, o al de elaborar una publicación atractiva que pudiese tener una fácil venta entre el público. También responde a unas circunstancias históricas en las que el jujutsu, después de rendir a sus pies a la sociedad deportiva parisina, había sido objeto de fuertes críticas (Brousse, 2000: 189 y ss.), afectando a su anterior imagen. Cualquier análisis del jujutsu en términos radicalmente positivos habría sido extemporáneo e impropio de un autor serio como André. De hecho, el suizo Armand Cherpillod, un famoso Campeón del Mundo de Lucha Libre de principios de siglo, elogiaba la obra de André en su Manuel de Jiu-Jitsu: "Proclamo que él es el primer autor que no se ha entusiasmado por la lucha japonesa y que haya visto las cosas tal como son" (Cherpillod, [1910?]: 5).

No obstante, la realidad francesa no era, desde luego, la de España $-\mathrm{y}$, hasta donde conocemos, la de otros países hispanohablantes (véase Gutiérrez, 2003; Uequín, 2005; Urbina, 2006)- donde el jujutsu apenas se conocía y aún habría de vivir su época de "apasionamiento". La edición en español de obra de André, por tanto, sí puede considerarse extemporánea, si bien muestra claramente la influencia francesa en la difusión del jujutsu.

\section{Tratado de Ju-jutsu y sus secretos ${ }^{4}$}

En 1907, justo el mismo año en que Sada Kazu Uyenishi "Raku" inauguraba en España la moda del jujutsu, la imprenta barcelonesa La Ibérica se apresuraba a publicar la obra Tratado de Ju-jutsu y sus secretos. Esta fecha, que no figura en el libro, es aportada por Llaverías (1910: 99) y por Palau (1948: I, 70), otorgando a este pequeño volumen de 131 páginas el privilegio de ser la primera obra publicada en España sobre el jujutsu, y, por extensión, sobre las artes marciales asiáticas. El carácter pionero del libro se refrenda, asimismo, en su propio prólogo, donde se afirma:

\footnotetext{
Al dar al público esta obrita que no tiene más mérito que el de ser la primera que se publica en España, no nos guía otro interés que la vulgarización de esta lucha; pues tanto bajo el punto de vista de la defensa como la del desarrollo muscular, es inmensamente superior á cuantas nos eran conocidas (p. 5).
}

La autoría del Tratado de Ju-jutsu y sus secretos no aparece en la publicación, donde se cita únicamente que la misma es una traducción del japonés realizada por C.D.T. No obstante, la realidad es que el tratado es en su gran mayoría una traducción del francés, y concretamente de la parte más técnica del libro Les Secrets du Jiu-Jitsu, escrito en 1906 por el profesor Ernest Régnier bajo el seudónimo de "Ré-Nié", sobrenombre con el que Régnier se había hecho popular en los círculos deportivos parisinos (Brousse, 2000). Asimismo, el resto de las técnicas que se detallan en el libro fueron tomadas de la obra The Text Book of Ju-Jutsu As Practised in Japan, escrita por Sada Kazu Uyenishi "Raku”, y publicada en Londres en 1905.

Con todo, y a pesar de la evidente falta de originalidad y sinceridad expuesta, el Tratado de Ju-jutsu y sus secretos merece ser destacado. No sólo por su carácter de obra pionera, sino también por una serie de rasgos japonizantes presentes en la edición que no aparecen en las fuentes originales 
de las que bebe, y que la convierten, en la modesta opinión del autor del presente trabajo, en la "joya" de estos primeros libros de artes marciales. Gracias a dichos rasgos se enfatizó el exotismo del jujutsu, una forma de lucha que apenas comenzaba a ser conocida en España (Gutiérrez, 2003; Gutiérrez y Espartero, 2004).

En cuanto a sus aspectos formales, la obra se presenta encuadernada con el sistema tradicional japonés, esto es, sin lomos. En su lugar, la unión de las páginas se ha realizado a partir de dos finos cordones dorados, dándole una apariencia de antigüedad. La portada y contraportada son de color negro o gris oscuro. En la portada, sobre el fondo, aparece un grabado también dorado en el que se representan, de adelante hacia atrás, unas cañas de bambú, varias nubes y un círculo que simboliza al sol o a la luna, todos ellos motivos clásicos japoneses. Los colores del conjunto sugieren que el modelo original posiblemente fuese una laca.

En la parte inferior del grabado figura también la típica firma de los artistas extremo orientales $-\mathrm{y}$ que también adoptaron diversos artistas europeos del periodo- consistente en una especie de sello con las iniciales del artista dispuestas geométricamente, imitando caracteres chinos. Por último, la tipografía de la palabra JU-JUTSU, en caracteres marcadamente orientalizantes inspirados en el katakana japonés, aparece en la parte derecha de la portada, en disposición vertical. Rasgo este último que, como bien señala Sue-Hee (1988: 99), también es en sí orientalizante.

Las abundantes ilustraciones -cuarenta y tres en total-, que forman parte del libro rezuman igualmente exotismo. Cada ilustración ocupa una página, encuadrándose en un marco que asemeja cañas de bambú. Las figuras representadas son varones japoneses practicando las diversas técnicas de la lucha japonesa. Lo que merece destacarse es que en la obra original del profesor Ré-Nié, de la que se copian la mayor parte de los dibujos, aparecen treinta y ocho planchas fotográficas del propio Ré-Nié con algunos de sus ayudantes -todos ellos occidentales- ejemplificando las técnicas. Por el contrario, en el Tratado de Ju-jutsu y sus secretos se evidencia un esfuerzo por dar a las figuras una apariencia oriental. Es más, en muchos de los dibujos las figuras aparecen con el cabello semitonsurado, en clara alusión a la estética samurái. Otro rasgo que añade, si cabe, aun más exotismo al libro es el color rojo de la tinta. Asimismo, las páginas carecen de numeración.

Con respecto al contenido del libro, su propio título de Tratado de JuJutsu y sus secretos remite al esoterismo del que inequívocamente se revestía la práctica. La obra se divide en cuatro partes: un breve pero muy interesante Prólogo, de cuatro páginas, una segunda parte de Gimnasia y Ejercicios Preliminares, que ocupa trece páginas, pasando a continuación a las partes principales, los Secretos de Combate - una nueva alusión al misterio que rodeaba al jujutsu-, de noventa páginas y en la que se describen diversas técnicas, y una serie de Ataques Varios, de veinte, también centrada en la descripción de algunas técnicas propias del jujutsu.

La obra es, por tanto, un trabajo eminentemente técnico, en el que no se han incluido algunas partes que componían las obras originales de RéNié -el debut del jujutsu en París, el jujutsu y su historia, y recomendaciones ligadas a la nutrición, a la respiración y a la higiene-ni de Sada Kazu Uyenishi - una interesantísima introducción que contiene nociones históricas y para el entrenamiento, un capítulo dedicado al equilibrio, y el estudio de diversas formas de caer sin hacerse daño-. Esta omisión muestra la intención del autor por crear una publicación, a modo de recetario, compuesta únicamente por los "secretos" o "trucos" del jujutsu, principal interés de la generalidad
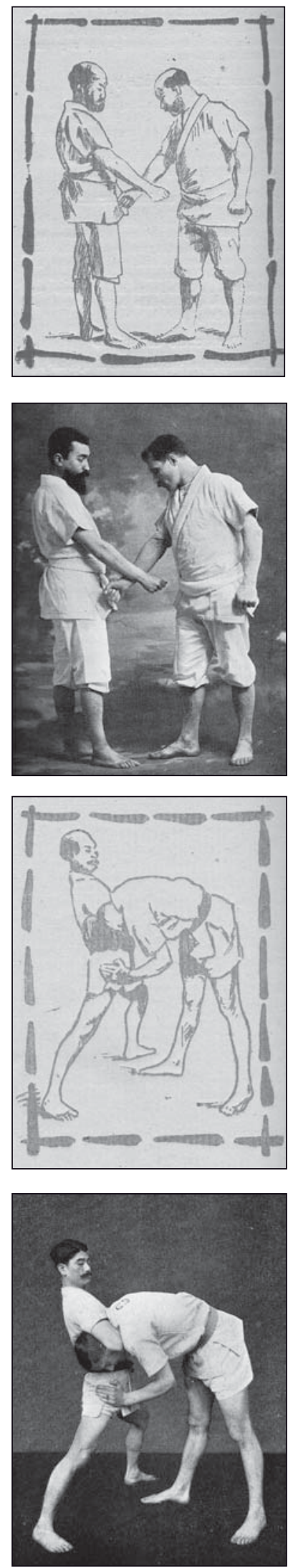

Ilustraciones del libro

Tratado de Ju-jutsu y sus secretos.

Debajo, las ilustraciones homólogas de los libros de Ré-nié y Raku. 

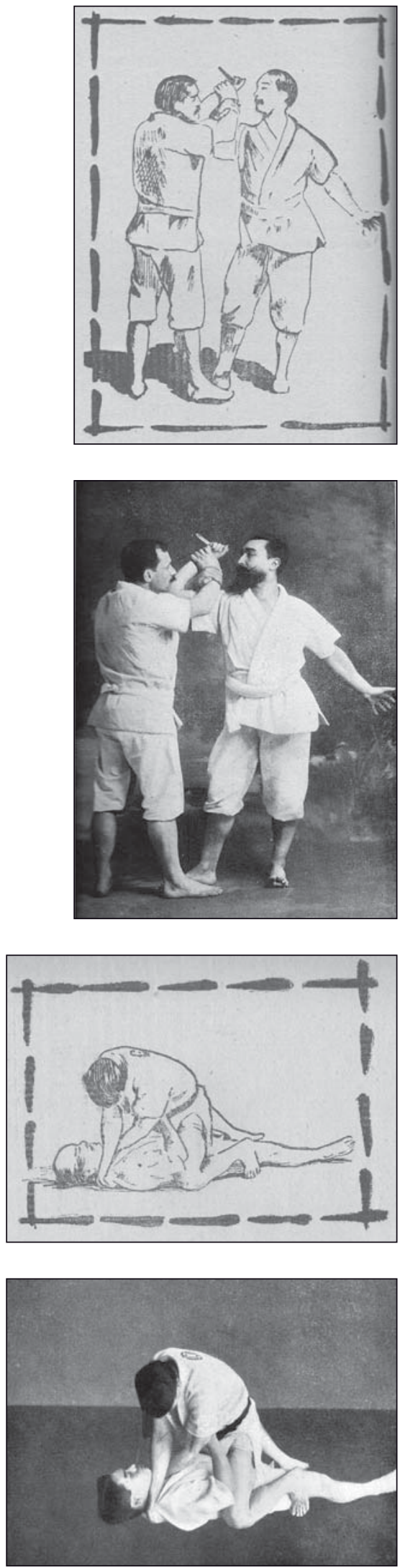

llustraciones del libro

Tratado de Ju-jutsu y sus secretos. Debajo, las ilustraciones homólogas de los libros de Ré-nié y Raku. de los posibles lectores. Pensamos que las técnicas que se toman del libro de Uyenishi, añadidas en la obra española, son consecuencia de las propias demostraciones que realizó este profesor en la Ciudad Condal. Así, el autor habría tratado de no olvidar las presas que más habrían impactado al público barcelonés.

Por otra parte, además de estos "secretos", el prólogo del tratado contiene referencias a la mayoría de las claves que definieron el interés por la lucha japonesa a principios del s. XX. Podemos citar entre las mismas la invencibilidad y el carácter utilitario del jujutsu:

\begin{abstract}
Bajo el punto de vista de la defensa personal, podría demostrarse con datos precisos que el Ju-jutsu es la más terrible lucha del mundo, sus presas son formidables, la dislocación, la fractura de un miembro y muchas veces la muerte son sus consecuencias.

Para hacerse cargo basta sólo con considerar que hay presas, que aun ejecutadas como á simple demostración la menor imprudencia puede acarrear la muerte del adversario (p. 6).
\end{abstract}

De hecho, dos de las técnicas que se explican en la obra son calificadas como "golpes mortales". Otro rasgo de la presentación del jujutsu sería su carácter de sistema gimnástico completo. Tras criticar el deficiente desarrollo corporal que proporcionaba el "método europeo", ya que "no es armónico, puesto que no hace trabajar por igual á los músculos de nuestro cuerpo", el autor señalaba:

\begin{abstract}
El desarrollo que produce el Ju-jutsu es en un todo armónico, por esto nos extraña la fuerza que nos muestran los ju-jutsistas en su cuello y piernas; el desarrollo producido por este ejercicio no olvida el más pequeño músculo, todos están desarrollados por igual; y como se comprende, el que lo practica goza de la rapidez y seguridad que tanto nos admira (p. 6).
\end{abstract}

El carácter deportivo del jujutsu también es referido en la obra. Frente al boxeo "brutal y supeditado á la fuerza muscular" la lucha japonesa "es una lucha bella, emocionante sin llegar a la barbarie", en la que prima la agilidad sobre la fuerza. Se trataba, por tanto, de un sport noble y superior:

En el combate de Ju-jutsu no hay restricciones como en las otras luchas, ni el ser vencedor consiste en que el contrincante toque con tal ó cual parte en el suelo, sino que es necesario que él mismo lo reconozca, que vea realmente que todos sus esfuerzos son inútiles, que está á completa merced de su adversario y que por lo tanto aún á su pesar debe confesarlo.

¿Qué lucha puede reducir al adversario á la impotencia sin que sufra el menor daño?

¿Ni qué lucha ofrece la ventaja de poder parar todos los golpes, cualquiera que sean estos como lo ofrece esta lucha? (...)

Este Sport no es de difícil comprensión sino que por su misma indole, por la diferencia grandisima que existe al compararlo con los demás, hace que para su regular dominio, sea necesario un largo, continuado y metódico ejercicio ( $p p$. 6-8).

El Tratado de Ju-jutsu y sus secretos es una obra que podemos considerar paradigmática en el contexto de la moda japonizante del jujutsu que conoció nuestro país al finales de la primera década del s. XX. La superficialidad de la moda del jujutsu -la superficialidad es un atributo inherente a la modaes paralela a la propia superficialidad del tratado, en el que no se abordan 
contenidos que los ya relativamente numerosos libros de jujutsu editados en Europa trataban con un cierto detalle. Del mismo modo, la presentación social del jujutsu como inmejorable sistema gimnástico, infalible método de defensa personal, y deporte completo y noble tiene un claro reflejo en el tratado. Este libro constituye, en definitiva, una muestra más del conjunto de expresiones que contribuyeron, en un primer momento, a la mitificación del jujutsu y por extensión de las artes marciales.

\section{Breve tratado de jiu-jitsu. Principales llaves de defensa que usan los más renombrados campeones de la lucha japonesa}

Poco tiempo después de publicarse el Tratado de Ju-jutsu y sus secretos, y también en Barcelona, la imprenta de la Viuda de J. Cunill editaba Breve tratado de jiu-jitsu. Principales llaves de defensa que usan los más renombrados campeones de la lucha japonesa [1908], una brevísima obra anónima de 16 páginas que se ubica en plena efervescencia del jujutsu en la Ciudad Condal. El año de publicación lo señalan Llaverías (1910: 99) y Palau (1949: II, 431), quienes añaden que, según informaciones del editor, ese mismo año se realizaría una segunda edición de la obra, ambas con una tirada de 2000 ejemplares, lo cual es clara muestra del interés despertado por el jujutsu.

Compone el libro una introducción de cuatro páginas, un total de seis técnicas o "llaves" (tres proyecciones, una luxación de pierna, una luxación de brazo y una estrangulación) con sus correspondientes ilustraciones, y tres páginas dedicadas al kuatsu. Las ilustraciones no son originales sino que se basan en las de la obra de André 100 lances de jiu-jitsu (ataques y quites). Merece la pena, sin embargo, advertir cómo al igual que realizase André, los dibujos también han sido modificados. En este caso, el experto ejecutante
Portada del libro Breve tratado de jiu-jitsu y algunas ilustraciones, donde puede apreciarse el "estilo Raku". Compárense con las ilustraciones homólogas del libro de Émile André.

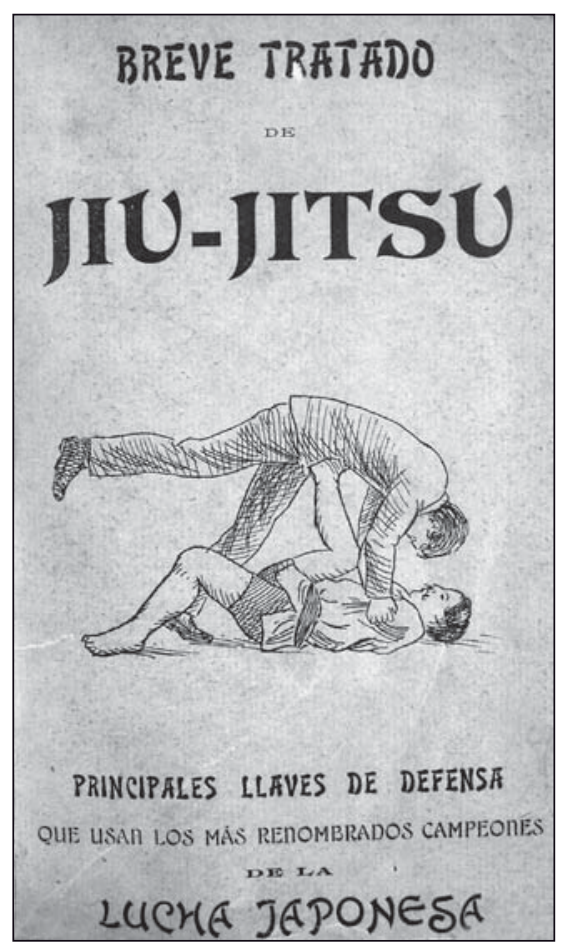

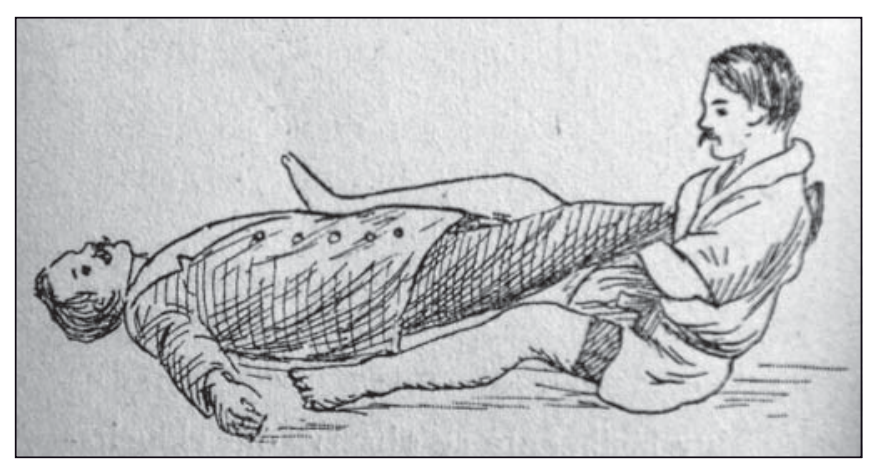

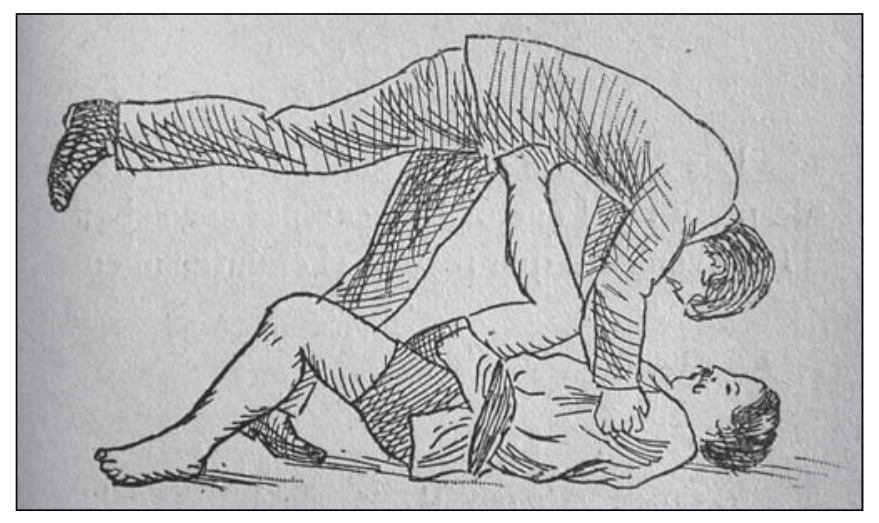

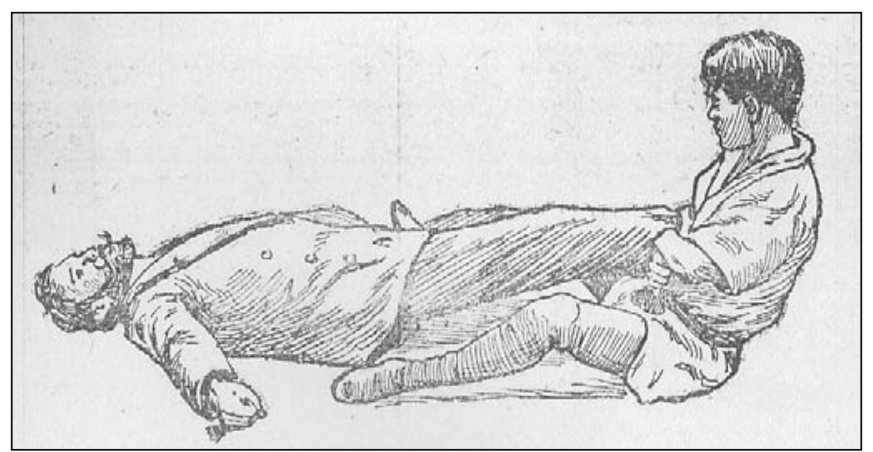

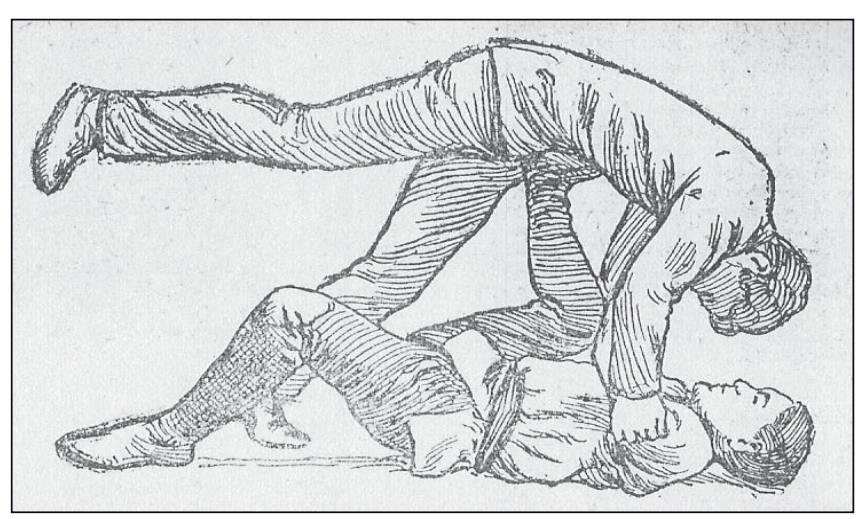




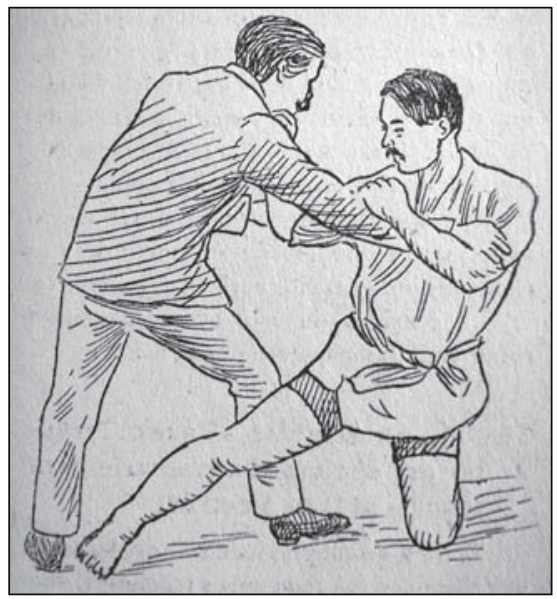

de las técnicas viste un pantalón corto, en vez del pantalón largo del "original" francés, y también se le ha añadido un fino bigote. Bajo nuestra interpretación existe un claro -y por otra parte inteligente- intento de asemejar la figura del experto a la de Sada Kazu Uyenishi "Raku", auténtico introductor de las artes marciales en Barcelona y en España, aunque en ningún momento se haga referencia al mismo.

Aunque, en propias palabras del autor, el único objeto de la obra es "Dar á conocer una pequeña noción de la principales llaves de defensa usadas más comúnmente" por los campeones japoneses, lo cierto es que no se escatiman alabanzas al jujutsu, cuyo fin era "poner en condiciones iguales de defensa al débil contra el fuerte y robusto, por medio de la agilidad y astucia combinadas" (p. 1). Como afirma el último párrafo de la introducción:

\begin{abstract}
Finalmente, y para terminar, resta declarar que el Jiu-Jitsu, además de constituir la mejor defensa propia en cualquier caso de sorpresa, por algún malhechor, constituye un sport altamente provechoso que, motivando el desarrollo constante de todos los músculos del cuerpo en general, resulta una gimnasia excelente para fortalecer el cuerpo humano. Y esta es la principal razón porque los países más progresistas lo reconozcan y adapten como un ejercicio de cultura física. (p. 4)
\end{abstract}

En relación al kuatsu, el autor lo deja con su halo de misterio. No describe ninguna técnica específica, sino que únicamente señala su carácter de "ciencia" y la dificultad de su aprendizaje, recomendando al neófito una total precaución en la práctica de técnicas complejas o peligrosas.

El Breve tratado de jiu-jitsu es, en conclusión, otro buen ejemplo de "publicación de moda", orientada a un consumidor masivo interesado superficialmente en dicha práctica en la que, sin aportarse nada nuevo, se reitera el imaginario propio del jujutsu a principios del s. XX.

\title{
Los secretos del "Jiu-Jitsu"
}

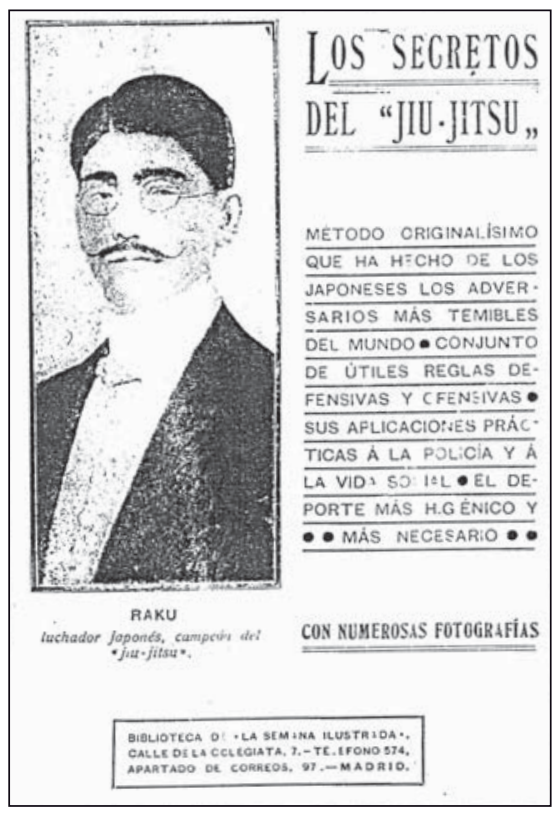

Portada del libro Los secretos del "Jiu-Jitsu".
Barcelona fue la ciudad española donde se editaron más libros sobre el jujutsu. A su zaga, la única capital española donde también se publicaron obras sobre la materia fue Madrid, si bien estas publicaciones tienen la peculiaridad de incluirse en publicaciones periódicas. La primera de estas obras fue el librillo por fascículos Los secretos del "Jiu-Jitsu", publicado por el semanario La Semana Ilustrada entre el 9 de enero y el 20 de febrero de 1909 y formando parte de la Biblioteca de la Semana Ilustrada.

Los secretos del "Jiu-Jitsu" es un trabajo de 28 páginas profusamente ilustrado nacido a consecuencia del interés creado por el jujutsu en Madrid tras las actuaciones de Sada Kazu Uyenishi "Raku", hecho que el autor resalta al disponer una fotografía de Uyenishi en la primera página de la obra y al referirse a él reiteradamente en el texto.

En cuanto a sus aspectos formales, la obra está redactada de seguido, careciendo de apartados o secciones. Puede diferenciarse, sin embargo, una primera parte general y una segunda parte que describe muy someramente algunos ejercicios y técnicas del jujutsu. Las ilustraciones no son originales sino reproducciones de varias obras extranjeras: The Text Book of Ju-Jutsu As Practised in Japan, de Sada Kazu Uyenishi "Raku", Les Secrets du Jiu-Jitsu, de Ernest Régnier, Jiu-Jitsu Combat Tricks: Japanese Feats of Attack $\mathcal{B}$ Defense in Personal Encounter, y Physical Training for Women by Japanese Methods, ambas de H. Irving Hancock, 
A pesar de su brevedad, el libro es rico en informaciones -casi todas ellas reduccionismos y estereotipos- sobre Japón y el jujutsu, en un tono excesivamente laudatorio, presentándolo como la panacea de los sistemas gimnásticos y de defensa personal. Entre los estereotipos relativos a la lucha japonesa ejemplificamos los siguientes:

La invencibilidad y la supremacía del débil sobre el fuerte

No es sólo el jiu-jitsu un excelente medio de defensa, sino que permite al más débil y al más calmoso luchar ventajosamente contra el más fuerte é impulsivo. (p. 5)

Veinte minutos de jiu-jitsu todas las mañanas hará fuertes a los débiles, poniéndolos en condiciones de defenderse contra todo ataque. (p. 6)

Constituye la salvaguarda de los hombres que no son hercúleos, el arma preciosa y siempre á mano de los pequeños y débiles para luchar victoriosamente contra los que van provistos de bastones, puñales, etc. (p. 7).

Por el jiu-jitsu podemos estar en condiciones de repeler la más bárbaras agresiones. (p. 10)

La cientificidad y la elegancia:

Asimismo es un deporte higiénico, práctico, de poco coste y también elegante, pues muchas de sus actitudes son realmente académicas. (p. 5)

Algunos deportes similares, tales como la lucha y el boxeo francés ó inglés, exigen un gran desarrollo de fuerza muscular. Todo es inútil para el jiu-jitsu, que más bien que un esfuerzo es una ciencia. (p. 7)

Alguien, muy espiritualmente, ha definido el jiu-jitsu diciendo que es "un método japonés que permite quebrantar al adversario sin que lo impecable de nuestro vestido sufra deterioro alguno" (p. 7)

Su carácter higiénico y saludable:

Mediante el jiu-jitsu pueden hallarse los mejores remedios para la neurastenia. (p. 5)

Como la gimnasia, mejor que la equitación y la esgrima, el jiu-jitsu debiera formar parte de la higiene de toda persona cuidadosa de su salud y de su defensa personal. Encierra, en sí, todos los principios de educación física y puede ser practicado por todos, incluso por la gente más modesta, puesto que no precisa la compra de ningún aparato. (p. 5)

La utilidad y practicidad:

10 Puede ser considerado como un excelente ejercicio físico y como un medio de defensa para los que no dispongan de recia musculatura. $2^{\circ}$ Se le debe estimar como un deporte que dá a sus iniciados valor y confianza en si mismos. $3^{\circ}$ Puede practicarse lo mismo en el campo que en el interior de las ciudades. $4^{\circ}$ Ejercita la gimnasia de la cabeza como la de las extremidades y el tronco. $5^{\circ}$ Constituye un remedio excelente contra la pereza. $6^{\circ}$ Los combatientes de peso distinto equilibran sus fuerzas. $7^{\circ}$ puede ser utilísimo á las señoras para defenderse en la calle de insolencias brutales. $8^{\circ}$ Para la policía, que en muchas ocasiones necesita penetrar en tenebrosos lugares, tiene el jiu-jitsu una decisiva ventaja, la de ser en la obscuridad de tanto efecto ó mayor que en plena luz. Tan convenientes argumentaciones deben llevarnos á hacer una conclusión: la de afirmar en concreto que el jiu-jitsu puede ser considerado como es el más útil de todos los deportes. (pp. II-12)
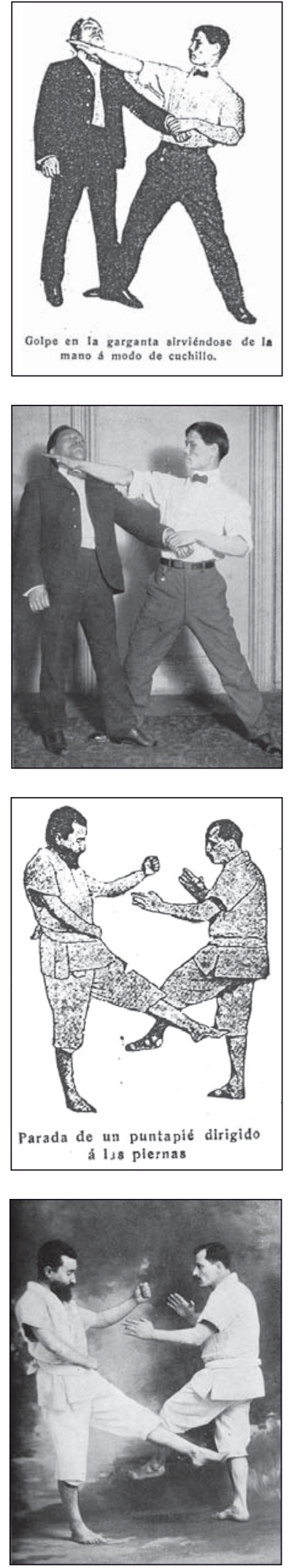

Ilustraciones del libro Los secretos del "Jiu-jitsu". Debajo, las ilustraciones originales de las obras Jiu-jitsu Combat Tricks y Les Secrets du Jiu-jitsu. 
Dos ilustraciones del libro Physical Training for Women by Japanese Methods que también aparecen en la obra española Los secretos del "Jiu-Jitsu".

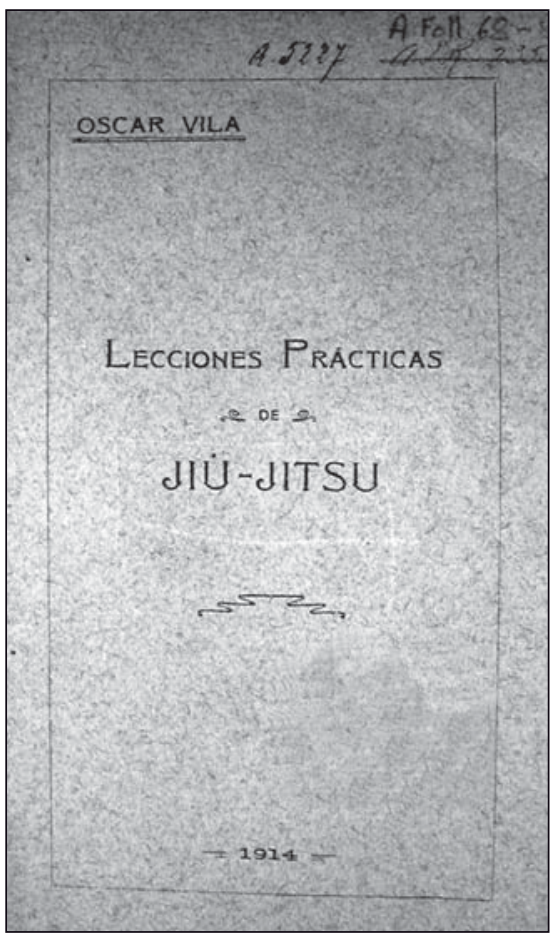

Portada del libro Lecciones prácticas de Jiú-jitsu.
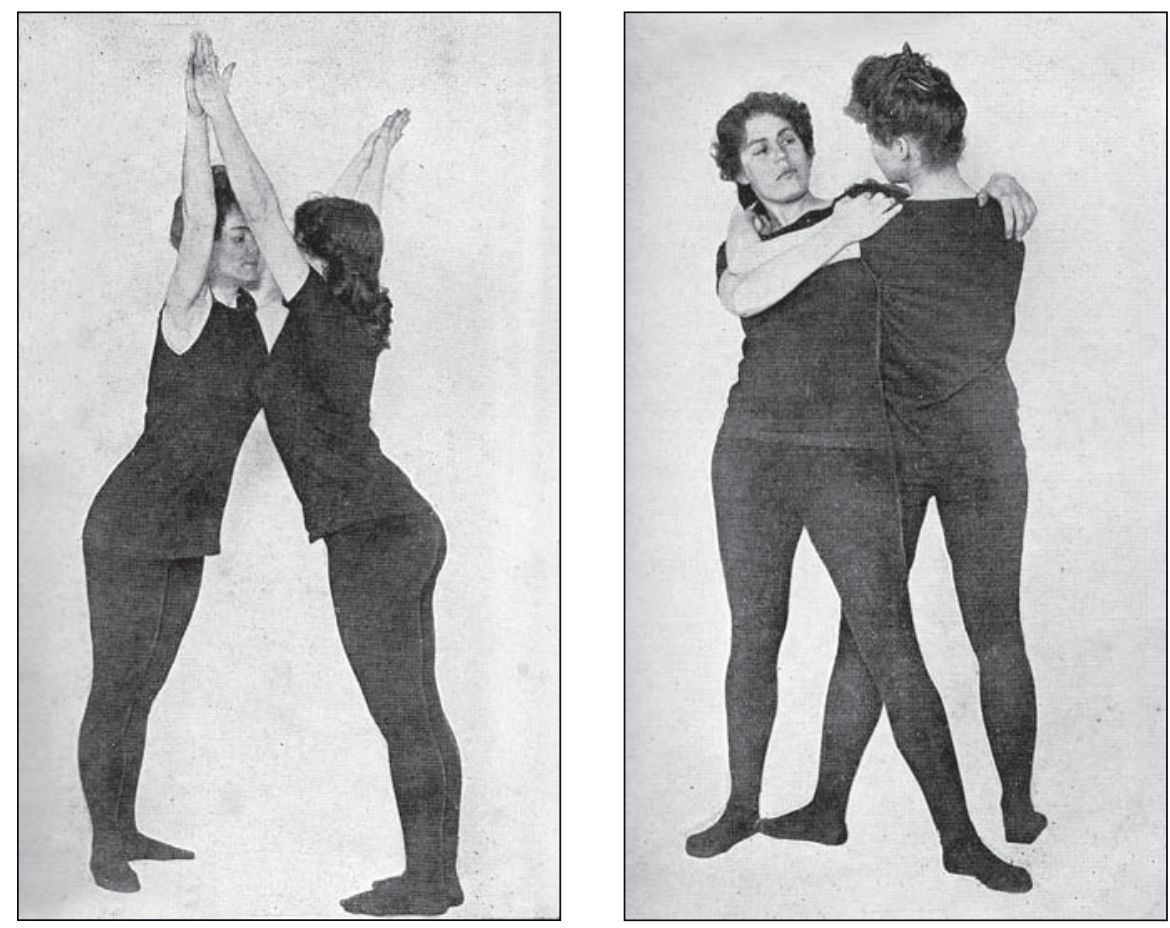

Y el esoterismo:

\begin{abstract}
El jiu-jitsu, bien aprendido, tiene resortes para producir instantáneamente, en un momento dado, la fractura de un miembro y aún la muerte del adversario. (p. 7).

[...] no es ocioso advertir que el jiu-jitsu encierra golpes excesivamente peligrosos que, dados bajo la influencia de enojo, pueden producir la inutilización de un miembro, la ruptura de numerosos músculos, la muerte misma. (p. 16)
\end{abstract}

Por lo que respecta a los estereotipos sobre Japón, muy abundantes, éstos abarcan numerosos aspectos relativos a las costumbres, tipología y forma de ser de los japoneses (alimentación, higiene, actividad física, carácter, fortaleza física y mental, ejército, etc.), todos ellos interpretados en clave también excesivamente admirativa como modelo a seguir en España, una antigua potencia venida muy a menos. En palabras del anónimo autor, gracias al jujutsu “[...] llegaría el de España á ser el mejor Ejército del mundo, Ejército capaz de renovar en los modernos tiempos las páginas brillantísimas de esa historia gloriosa, asombro del mundo en pasadas centurias" (p. 10), ya que, a pesar de la admiración manifestada por Japón, los japoneses no dejaban de ser "amarillos" (véase al respecto Rodao, 2002), y, por tanto, inferiores: "Pertenecemos nosotros á una raza más fuerte que la raza amarilla" (p. 10).

\section{Lecciones prácticas de Jiú-Jitsu}

Según señala Uequín (2005), el jujutsu/judo llega a Argentina en 1906, cuando el Capitán de Navío Adolfo M. Díaz lograba llevar al país a Yoshio Ogata y Kotoku Watanabe, dos discípulos directos de Jigoro Kano, para que enseñasen en la Escuela Naval Militar. Varios años después, en 1914, Óscar Vila, que se presentaba a sí mismo como "Profesor Argentino de Jiú-Jitsu" y "ExInstructor de la Policía de la Provincia de Buenos Aires", publicaba 

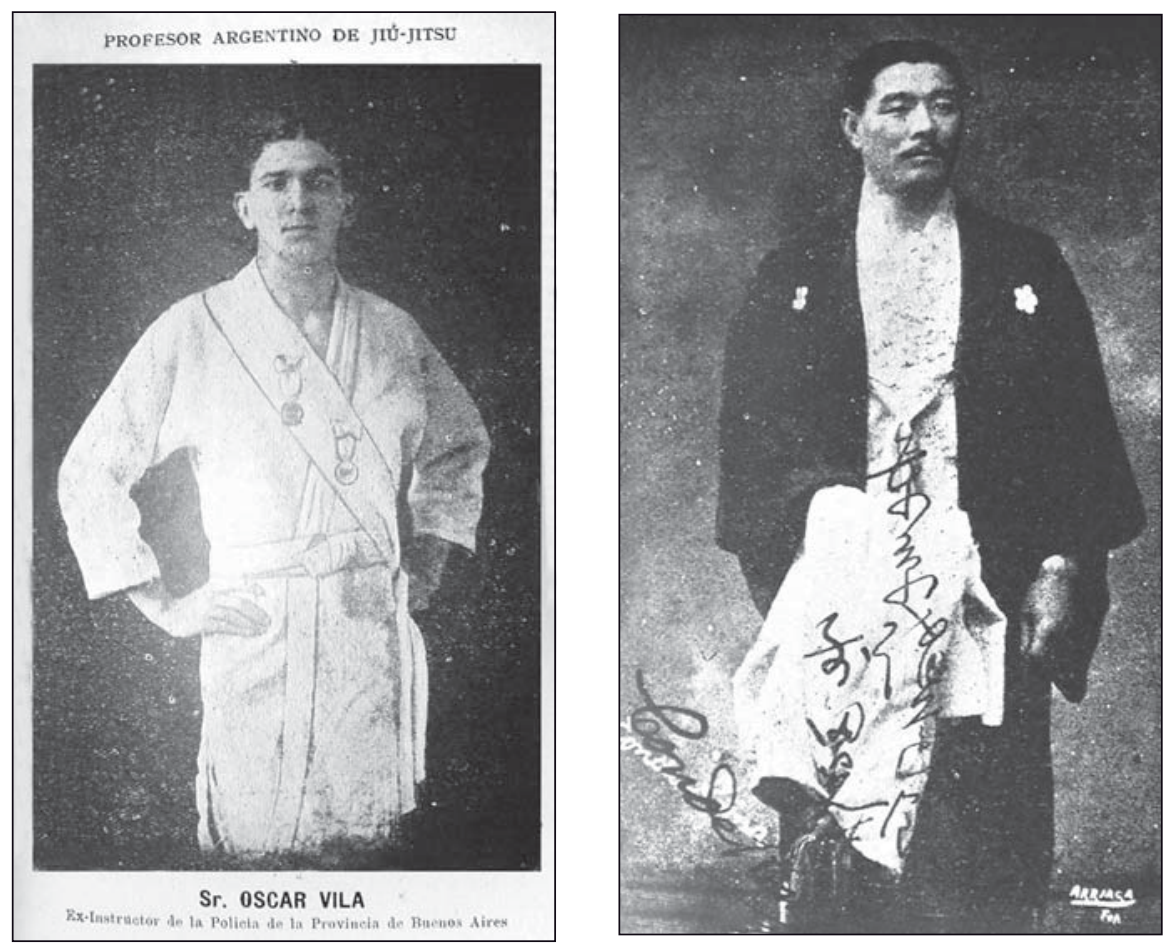

Retratos del autor y del famoso Mitsuyo Maeda "Conde Koma".

Lecciones prácticas de Jiú-Jitsu, una obra de 46 páginas que probablemente fuese la primera publicada en Argentina sobre la materia.

Óscar Vila, al igual que Émile André, fue un divulgador de la cultura física en su país, principalmente en la provincia de Santa Fe, escribiendo obras como ¿Conviene la gimnasia al sexo débil?, Gimnasia Respiratoria, Ataxia locomotriz. Reeducación gimnástica de los músculos afectados, y Programas de Ejercicios Físicos para las Escuelas Primarias. Desconocemos la formación del profesor Vila respecto al jujutsu, pero pudo tener algún tipo de relación con Mitsuyo Maeda "Conde Koma", ya que en la quinta página de la obra figura una fotografía dedicada al autor por parte del campeón japonés.

Lecciones prácticas de Jiú-Jitsu es un tratado técnico estructurado en diversas secciones, siendo la mayor parte de las tres primeras (Prólogo, Conocimientos necesarios para practicarlo, Entrenamiento) una traducción del capítulo que sobre el jujutsu escribiese Albert Surier en la enciclopedia Les Sports modernes illustrés (París: Larousse, [1095]).

Continúa esta parte introductoria con tres secciones (La gimnasia en el Jiú-Jitsu, El Jiú-Jitsu de "Salón" y el Jiú-Jitsu "Libre", y "Asaltos de Jiú-Jitsú") en las que merece destacarse la diferenciación que realiza el autor entre el jujutsu de "Salón" y el jujutsu "Libre", basada en la dificultad y peligrosidad de los golpes empleados en este último.

Siguiendo esta clasificación, las dos secciones técnicas del libro describen 26 Golpes y Quites de "Lucha de Salón", y 17 Golpes y Quites de "Lucha Libre", concluyendo la obra con dos secciones finales dedicadas al Kuatsu -según el propio autor reconoce, toma esta sección de Émile André, concretamente de la obra 100 lances de jiu-jitsu- y a la distribución de sus enseñanzas en tres meses con un total de 24 lecciones. El libro carece de ilustraciones excepto la ya comentadas del Maeda más otra del autor vistiendo un gi condecorado.

Como ya se ha apuntado, el autor considera el jujutsu de salón como la manifestación "deportiva" de la práctica, describiendo unas sencillas 
normas para los "Asaltos de Jiú-Jitsu”. El jujutsu libre, por su parte, sería aquel aplicado en situaciones de autodefensa. Sin embargo, Vila incluye tanto en uno como en otro tipo de jujutsu una serie de técnicas sin justificación aparente-por ejemplo, en el jujutsu de salón golpes con el canto de la mano, con el antebrazo, con el pie, presión de nuez y oídos, o luxaciones de cuello-. Tampoco realiza algún tipo de justificación sobre la progresión de enseñanza que propone.

Al margen de los aspectos técnicos, la sección introductoria expone el conjunto de supuestas virtudes del jujutsu que hemos venido señalando en obras precedentes (invencibilidad, elegancia, carácter saludable, etc.):

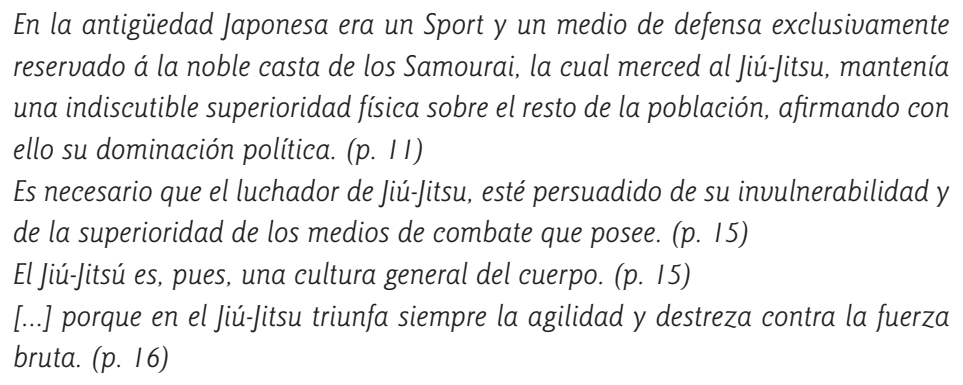

La obra de Óscar Vila es, en resumen, otra muestra más de tratado técnico de jujutsu adornado con las pinceladas coloristas de su imaginario, un imaginario creado a principios del s. XX y que de un modo relativamente rápido se difundía a nivel global.

Portada del libro Destreza. Método práctico para prender, asegurar, conducir delincuentes y de luchar con éxito contra ellos si se oponen á la detención.

Esta obra se publicó en la Revista Técnica de la Guardia Civil.

= Capitanes $=$

GISTAU Y SONGEI

\section{DESTREZA}

Método práctico para prender, asegurar, conducir delincuentes y de luchar con éxito contra ellos :-: si se oponen á la detención. :-:

Indlspensable á los GUARDIAS CIVILES, Agentes de VIgllancla, Guardlas de Segurldad, Carablnerós $y$, en general, a cuantos constituyen la salvaguardla de contilate

\section{Destreza. Método práctico para prender, asegurar, conducir delincuentes}

Uno de los ámbitos donde el jujutsu despertó un mayor interés fue el de las Fuerzas Armadas, tanto en Japón como fuera de él. Desde principios del s. XX, los ejércitos de numerosos países como Alemania, Argentina, Estados Unidos, Francia, Inglaterra o Italia contrataron personal especializado en la lucha japonesa para instruir en diversos cuerpos e instituciones militares (Brousse y Matsumoto, 1999, 2005; Toschi, 1993; Uequín, 2005).

En España, el interés de las Fuerzas Armadas por el jujutsu sería bastante tardío, a pesar de que varias publicaciones advirtiesen de su utilidad y asimilación como método de adiestramiento en los principales ejércitos del mundo (Gutiérrez, 2003). De hecho, el primer libro que conocemos sobre la aplicación del jujutsu en el ámbito de las Fuerzas Armadas no se publicaría hasta 1915, cuando otros países ya contaban desde hace tiempo con tratados sobre la materia (Dudenbostel, 1943; Smith, 1961; Nelson, 1988; Brousse, 2000).

Destreza. Método práctico para prender, asegurar, conducir delincuentes y de luchar con éxito contra ellos si se oponen á la detención es una obra de 75 páginas publicada en la Revista Técnica de la Guardia Civil. Sabemos que uno de sus autores, el capitán Miguel Gistau Ferrando, fue autor de diversos libros de temática militar, aunque desconocemos su relación con el jujutsu, al igual que la del capitán Songel.

El libro de Gistau y Songel es un tratado técnico estructurado en capítulos que describen diversos procedimientos útiles al guardia civil: procedimientos preventivos, diversos modos de inmovilizar a un 

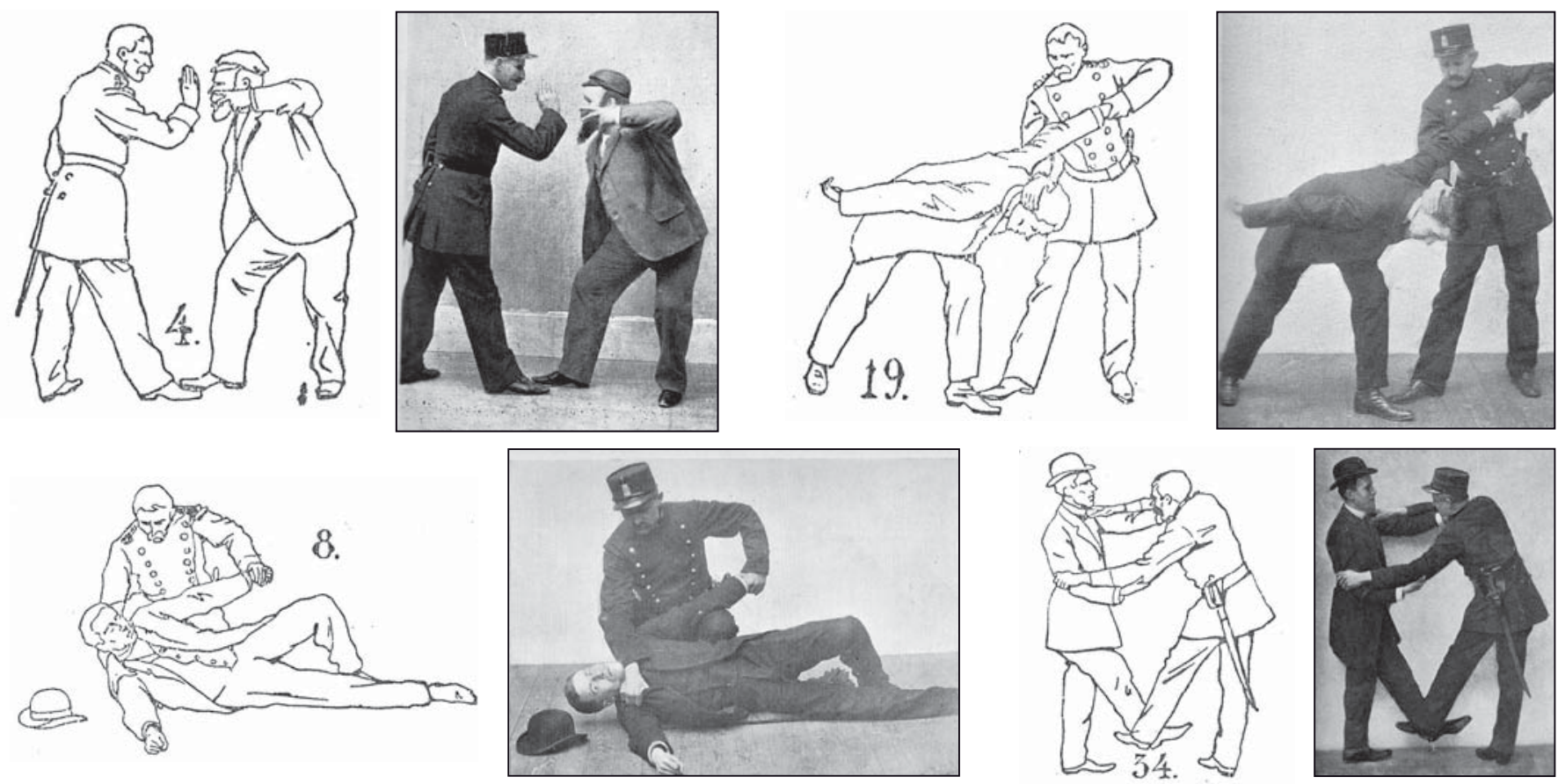

hombre, detención de un fugitivo, modos distintos de echar a tierra a un hombre, conducir a un hombre a cuestas, diversos modos de obligar a marchar a un detenido, procedimientos defensivos, defensa contra gentes armadas y conducciones de presos. Terminan de dar forma a la obra dos capítulos introductorios -"Al que leyere-. Importancia y necesidad de estos conocimientos" y "Generalidades y consejos"- y una conclusión. Acompañan al texto un total de 108 ilustraciones sobre los procedimientos descritos.

Aunque en ninguna parte de la obra se haga referencia explícita la influencia del jujutsu en la misma, ésta es más que evidente. De hecho, la mayor parte del tratado es una adaptación de Le Jiu-Jitsu pratique. Méthode de defense et d'ataque enseignant 100 moyens d'arrêter, inmobiliser, terrasser, conduire ou emporter un malfaiteur, même armé, escrito por el Comisario de Policía de París Charles Péchard en 19065. Esta influencia se aprecia tanto en los textos como en las ilustraciones, si bien hay que reconocer a los autores de la obra española el haber seleccionado y reestructurado los contenidos del original francés, así como el haber añadido otros como por ejemplo las conducciones de presos o "los peligros del sable para quien lo usa". Las ilustraciones -fotografías en el original francés, dibujos en la obra española- son idénticas excepto por haberse suprimido la típica gorra del gendarme francés.

Pensamos que la omisión de referencias al jujutsu es totalmente deliberada, consecuencia de un momento en que la moda del jujutsu ya había pasado y no era pertinente acudir a su imaginario para validar los métodos propuestos. Dichos métodos debían ser bastante novedosos, ya que los propios autores justificaban su enseñanza, a pesar de los recelos que ello pudiera provocar, en el hecho de que los mismos formaban parte de la formación de los cuerpos policiales fuera de España.

La obra, "Indispensable á los GUARDIAS CIVILES, Agentes de Vigilancia, Guardias de Seguridad, Carabineros y, en general, á cuantos
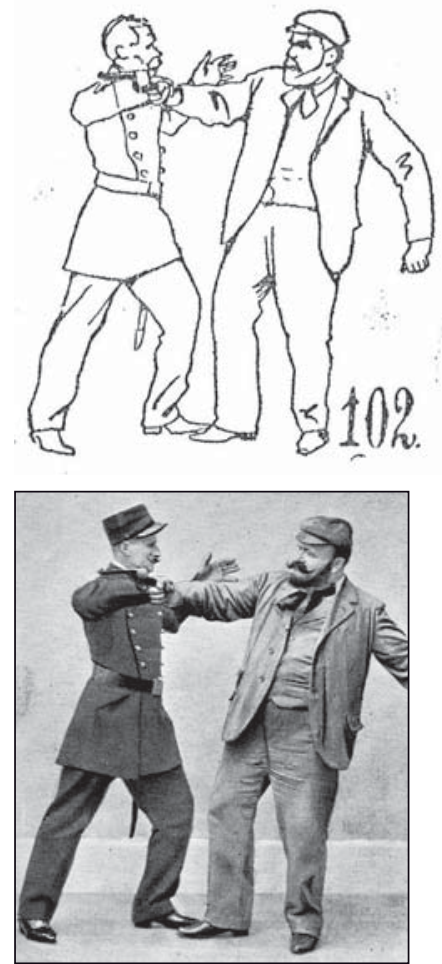

Fotografías de la obra Destreza..., junto con los originales de la obra de Charles Péchard Le Jiu-Jitsu pratique. Méthode de defense et d'ataque enseignant 100 moyens d'arrêter, inmobiliser, terrasser, conduire ou emporter un malfaiteur, même armé. 
Una de las aportaciones originales del trabajo de los Capitanes Gistau y Songel son los capítulos dedicados a los "Peligros del sable para quien lo usa" y "Conducciones de presos".
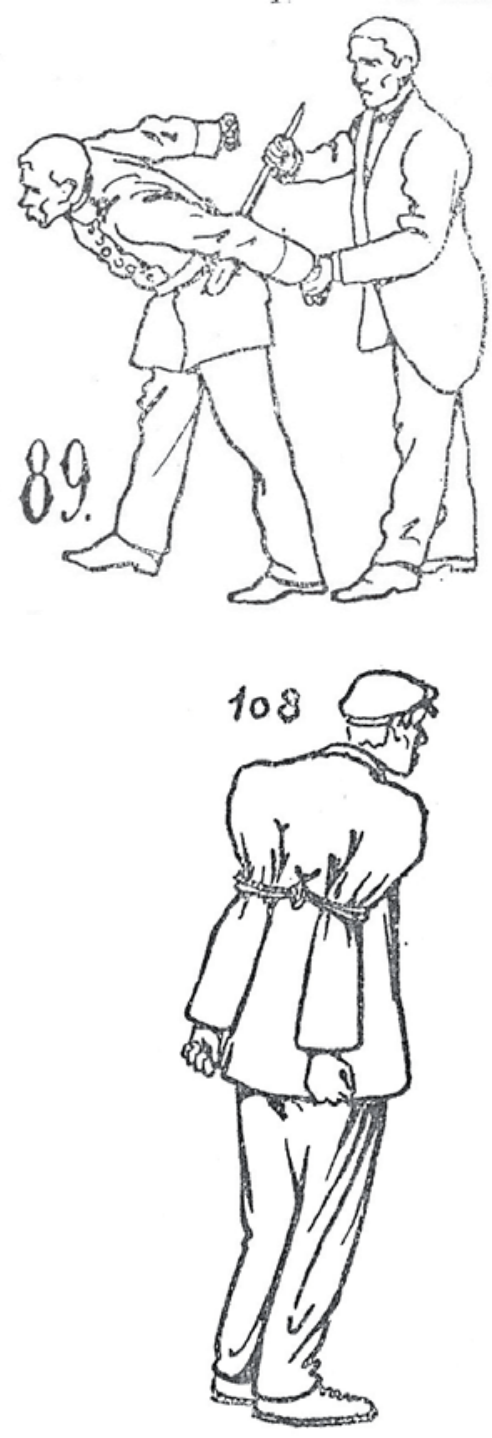

constituyen la salvaguardia de la Sociedad" (p. 1), es posiblemente el trabajo más serio de cuantos se publicaron en este primera época de difusión del jujutsu en España. Gistau y Songel reelaboran un trabajo específico y útil al Guardia Civil y demás agentes de seguridad, imbuido de un profundo concepto de servicio social. Justifican de un modo práctico los diversos procedimientos que describen, argumentando la necesidad de utilizarlos únicamente cuando es necesario y de un modo proporcional, señalando además la importancia de la práctica para su completo control y dominio. Asimismo, huyen del cúmulo de estereotipos presentes en otras obras del mismo periodo, si bien puede apreciarse alguno de ellos:

\begin{abstract}
No requieren, como á primera vista podría creerse, los procedimientos de ataque y defensa individual que habremos de exponer, grande vigor físico, aunque, como es lógico, es una gran ventaja poseerlo. Con estas prácticas se tiende á proporcionar el triunfo á la destreza y á la agilidad, haciendo que la inteligencia sobrepuje á la fuerza bruta (p. 8).
\end{abstract}

Lamentablemente, la obra de los capitanes Gistau y Songel no tuvo la repercusión esperada, quedando como una mera declaración de intenciones sin repercusión efectiva. Ésta y otras tentativas para introducir la lucha japonesa en las Fuerzas Armadas de España no tuvieron éxito hasta muchos años después, en un segundo periodo de evolución del jujutsu/judo (Gutiérrez, 2003).

\section{Otras obras con secciones dedicadas al jujutsu}

Concluimos la presente revisión de los primeros libros sobre artes marciales publicadas en español haciendo referencia a tres obras que si bien no son monografías sobre la materia sí que dedican alguna sección o capítulo a su estudio. El primero de estos trabajos lleva por título Los Sports de moda. Foot-ball. Water-polo. Jiu-Jitsu, y fue publicado en Barcelona sobre $1910^{6}$. Del autor, el Barón René de Montespín, no conocemos ninguna otra obra ni tenemos más referencias? ${ }^{7}$. Dentro del conjunto del libro, cuya extensión es de 123 páginas, la parte dedicada al jujutsu comprende únicamente doce, que son una traducción literal del ya comentado capítulo que escribió Albert Surier en la enciclopedia Les Sports modernes illustrés. La única diferencia entre ambos trabajos consiste en que las fotografías del original francés, en un total de doce, se han sustituido por dibujos.

Una segunda obra que merece ser resaltada es Modos de defenderse en la calle sin armas. Lecciones prácticas de boxeo, jiu-jitsu, lucha greco-romana, etc., un trabajo de 141 páginas con numerosas ilustraciones publicado en 1914 por Joan Bardina Castará bajo el seudónimo de Dr. Saimbraum. Este libro conocería dos nuevas ediciones en 1930 y 1939.

Joan Bardina (1877-1950), una eminente figura del movimiento de renovación pedagógica catalana de principios del s. XX, fue autor de diversos trabajos relativos a la actividad física y a la higiene ${ }^{8}$. Como tal, no tenemos constancia de que tuviese algún tipo de formación respecto al jujutsu u otros deportes de combate, aunque es innegable que tenía una formación más que suficiente como para poder elaborar, traducir o adaptar un tratado divulgativo sobre estas materias.

Modos de defenderse en la calle sin armas es un tratado orientado hacia la defensa personal que aglutina técnicas de combate de diversos estilos. 

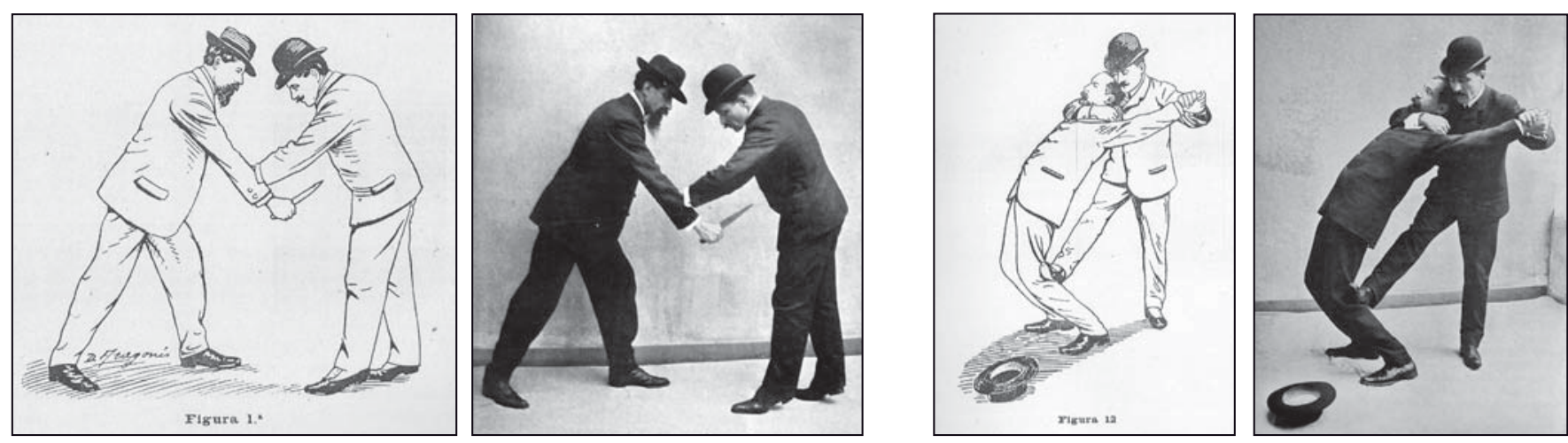
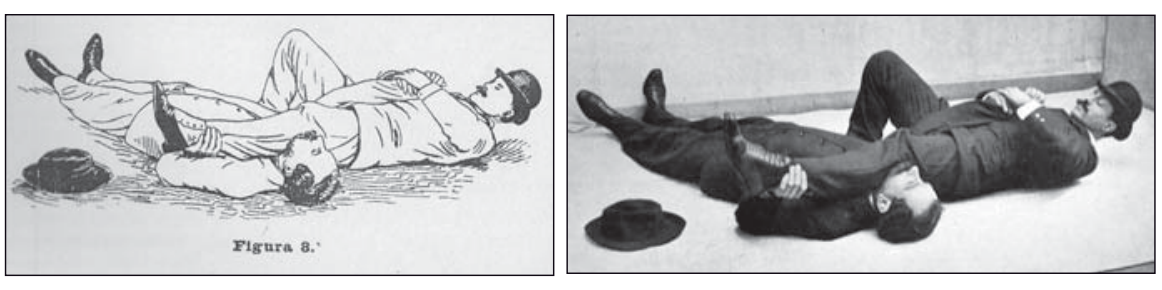

Como el propio autor indica, "[...] no hemos de referirnos exclusivamente a ninguno de estos deportes; sino que de cada uno de ellos tomaremos cuanto creamos que pueda servir al lector para que se defienda" (p. 15). Así, la estructura del libro consta de dos partes; la primera se centra en las técnicas a distancia (puñetazos, golpes con los pies, zancadillas, torceduras, golpes con la cabeza), mientras que la segunda estudia el combate cuerpo a cuerpo (defensas contra agarres, golpes, defensas contra golpes "de apache").

En este conjunto de procedimientos, y aunque de un modo totalmente desapasionado, Bardina reconoce al jujutsu su aportación en la lucha cuerpo a cuerpo y en las técnicas de "torcedura", puesto que el jujutsu "Es un deporte que se basa exclusivamente en fenómenos anatómicos, y puede decirse que quien lo emplea hace todo lo posible para obligar a la parte del cuerpo atacada a oponerse a las funciones que la naturaleza le ha señalado" (p. 134). No obstante, Bardina considera al jujutsu inferior al boxeo -un deporte de mayor actualidad por aquellas fechas-, recomendándolo únicamente como complemento a éste.

Por último, durante la segunda década del s. $\mathrm{XX}^{9}$, un anónimo autor bajo el exótico y evocador seudónimo de Rit-Jou-Ku, publicaba Modo de defenderse sin armas. La defensa en la calle. Cómo hacerse inexpugnable (B. Bauza: Barcelona), libro que formaba parte de la colección Biblioteca de Sports y Juegos, "Indispensable a todo buen sportman" (p. 6). Se trata de un trabajo de 127 páginas ilustrado con un total de 16 fotografías, enfocado hacia la defensa personal desde un punto de vista técnicamente ecléctico.

La obra comienza con un prefacio al que siguen ocho capítulos, uno introductorio (Los Sports de Defensa) y siete dedicados a diversos tipos de técnicas (Los puñetazos, Los Puntapiés, Golpes de cabeza, Las torsiones, Los golpes de jiu-jitsu, Lección gráfica de una defensa sin armas y Las torsiones de jiu-jitsu). Según el autor, no existe ninguna forma de lucha ideal, sino que es la combinación de diversos sistemas de lucha lo que puede dotar al individuo de una defensa personal efectiva. Así, considera que "El verdadero sport de defensa, no puede dudarse que es el bóxer. El bóxer completado por algunas lecciones de lucha greco romana y otras de jiu-jitsu" (p. 17), si bien más adelante rechaza la lucha para concluir que "una fusión, una mezcla del bóxer y el jiu-jitsu es lo que constituye el verdadero sistema de defensa en la calle" (p. 56).

\section{LOS SPORTS DE MODA}

\section{Foot-ball}

Según los consejos de M. M. Tunmer y Fraysse

\section{(W)ater-polo Jill-Jitsu}

POR EL BARÓN RENE DE MONTESPIN

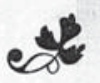

EDITORIAL IBERO-AMERICANA Valencia, 209 BARCELONA

Contraportada y algunas ilustraciones del libro Los Sports de moda.

A la derecha, las fotografías originales del capítulo de Albert Surier sobre jujutsu, publicado en la enciclopedia Les Sports modernes illustrés 

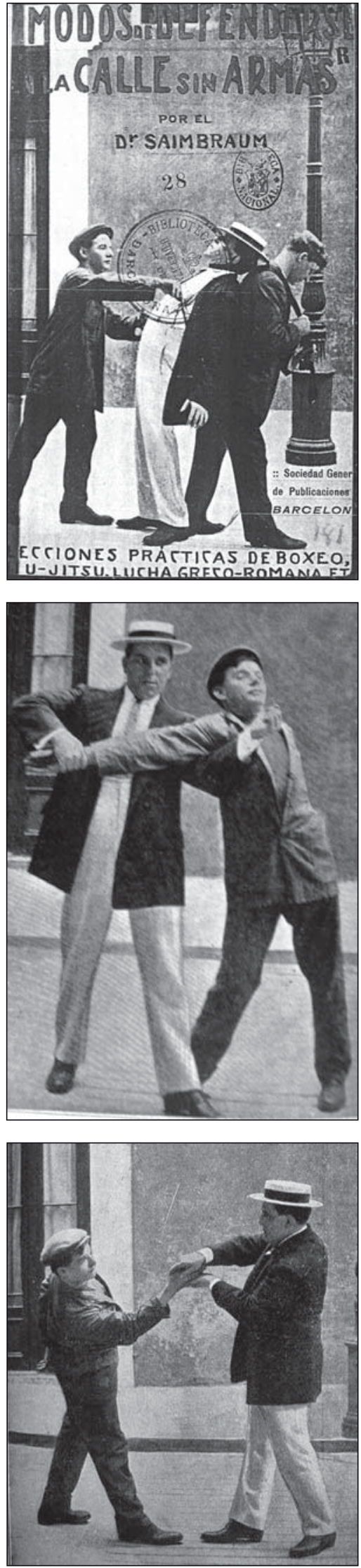

Portada y algunas ilustraciones del libro Modos de defenderse en la calle sin armas.
Dentro de esta propuesta, Rit-Jou-Ku, al igual que realizara Bardina, reserva las torsiones (de dedos, manos y brazos) al dominio del jujutsu, señalando tanto su dificultad como su efectividad. No en vano "el jujutsu es astucia, sagacidad", y "un estudio anatómico del cuerpo humano, que tiende especialmente a encontrar la mayor suma de facilidad en el esfuerzo para producir el mayor dolor posible en el contrario" (p. 55).

\section{Conclusión}

El análisis realizado de las primeras obras publicadas en lengua española sobre el jujutsu revela claramente su falta de originalidad, siendo éstas en su mayor parte traducciones y adaptaciones más o menos literales de obras escritas en inglés y fundamentalmente en francés. Esta realidad es consecuente con un momento histórico en el que la visión francesa impregna el mudo del arte y de la moda, así como la percepción de lo oriental. Parafraseando a Klaus Berger (1993: 3), podríamos decir que Lo que contaba no era la cultura de Japón, ni incluso la realidad objetiva del jujutsu, sino simple y puramente aquellas cosas que la sociedad deportiva parisina quería ver y era capaz de ver ${ }^{10}$.

Partiendo de esta realidad, no obstante, los tratados estudiados merecen ser destacados tanto como conjunto como en su individualidad. Ya sea por su atractiva y exótica edición, por sus contenidos, por la gran difusión que alcanzaron en su época, o por presentarnos a personas, instituciones y hechos relevantes, suponen una pieza de inestimable valor para la reconstrucción de la historia de las artes marciales asiáticas.

\section{Agradecimientos}

El autor desea agradecer al Dr. Michel Brousse su ayuda en la localización de algunas de las publicaciones francesas que sirvieron de inspiración para las obras comentadas en el presente trabajo.

\section{Bibliografía}

André, Émile (1896). Manuel théorique et pratique d'Escrime: (Fleuret, épée, sabre...). París: Garnier Frères.

André, Émile (1897). Manual de esgrima, florete, espada y sable. París: Garnier Hermanos.

André, Émile [1898]. L'art de se defender dans la rue. París: Ernest Flammarion.

André, Émile [1901]. Les Trucs du duel, pistolet, épée, sabre. París: Ernest Flammarion.

André, Émile (1904). Manuel de boxe et de canne. París: Garnier Frères.

André, Émile [1905]. 100 Façons de se défendre dans la rue avec armes (canne, bàton à deux mains, couteau et poignard, canne à épée, coup de poing américain, revolver, pistolet automatique). París: Ernest Flammarion.

André, Émile [1905]. 100 Façons de se defender dans la rue sans armes. París: Ernest Flammarion.

André, Émile [1906]. 100 coups de jiu-jitsu (coups et parades). París: Ernest Flammarion. 
André, Émile (1906). 100 lances de jiu-Jitsu. (Ataques y quites). París/México: Librería de la Viuda de Bouret.

André, Émile [1909]. Manual práctico de pugilato, lucha de box, esgrima del bastón y del palo. París: Garnier Hermanos.

Berger, Klaus (1993). Japonisme in Western Painting from Whistler to Matisse. Cambridge: Cambridge University Press.

Blanco y Sánchez, Rufino (1927). Bibliografía General de la Educación Física con datos copiosos referentes a biología, antropología, anatomía, fisiología, higiene, eugénica, puericultura, paidología, pedagogía y otras ciencias fundamentales del ejercicio corporal educativo. Tomo I y II. Madrid: Hernando.

Brousse, Michel (2000). Les origines du judo en France. De la fin du XIX siécle aux années 1950. Historie d'une culture sportive (Tesis Doctoral). Burdeos : Universidad de Burdeos.

Brousse, Michel y Matsumoto, David (1999). Judo. A Sport And A Way Of Life. Seúl: F.I.J.

Brousse, Michel y Matsumoto, David (2005). Judo in the U.S. A Century of Dedication. Berkeley (California): North Atlantic Books.

C.D.T. (Trad.) [1907]. Tratado de Ju-jutsu y sus secretos. Barcelona: La Ibérica.

Cherpillod, Armand [1910?]. Manuel de Jiu-Jitsu. A l'usage des societés de gymnastique, de l'armée et du public en général. Paris: Librairie Générale d'Education.

Dudenbostel Jones, Helen (comp.) (1943). Judo, Jiu-Jitsu and Hand-to-Hand Fighting: A List of References. Washington: The Library of Congress.

Gistau \& Songel (1915, enero). "Destreza. Método práctico para prender, asegurar, conducir delincuentes y de luchar con éxito contra ellos si se oponen á la detención". Madrid: s.n. Obra publicada en la Revista Técnica de la Guardia Civil, 61, 1-75.

Gutiérrez García, Carlos (2003). Introducción y desarrollo del judo en España (de principios del siglo XX a 1965): El proceso de implantación de un método educativo y de combate importado de Japón. León: Servicio de Publicaciones de la Universidad de León.

Gutiérrez García, Carlos (2004). "Estudio de la obra tratado de Ju Jutsu y sus secretos, primer libro editado en España sobre las artes marciales". En VV.AA. (Coords.), Dimensión histórica, cultural y deportiva de las luchas, Gran Canaria: Cabildo Insular de Fuerteventura y ACCEDEL, pp. 75-82.

Gutiérrez García, Carlos y Espartero Casado, Julián (2004). "Jujutsu’s image in Spain Wrestling Shows. A historic review". Journal of Asian Martial Arts, 13 (2), 9-31.

Hancock, H. Irving (1904). Jiu-Jitsu Combat Tricks: Japanese Feats of Attack $\mathcal{G}$ Defense in Personal Encounter. New York: G.P. Putnam's Sons.

Hancock, H. Irving (1904). Physical Training for Women by Japanese Methods. New York: G.P. Putnam's Sons.

Hancock, H. Irving (1905). Jiu-Jitsu, méthode d'entraînement et de combat. Paris/Nancy: Berger-Levrault.

Hancock, H. Irving (1906). Le Jiu-Jitsu et la femme: entrînement physique féminin. Paris/Nancy: Berger-Levrault \& Cie.

Hancock, H. Irving e Higashi, Katsukuma (1905). The Complete Kano JiuJitsu. Nueva York: G. P. Putnam \& Sons.

Hancock, H. Irving e Higashi, Katsukuma (1908). Traité complet de Jiu-Jitsu. Méthode Kano. Paris/Nancy: Berger-Levrault \& Cie.
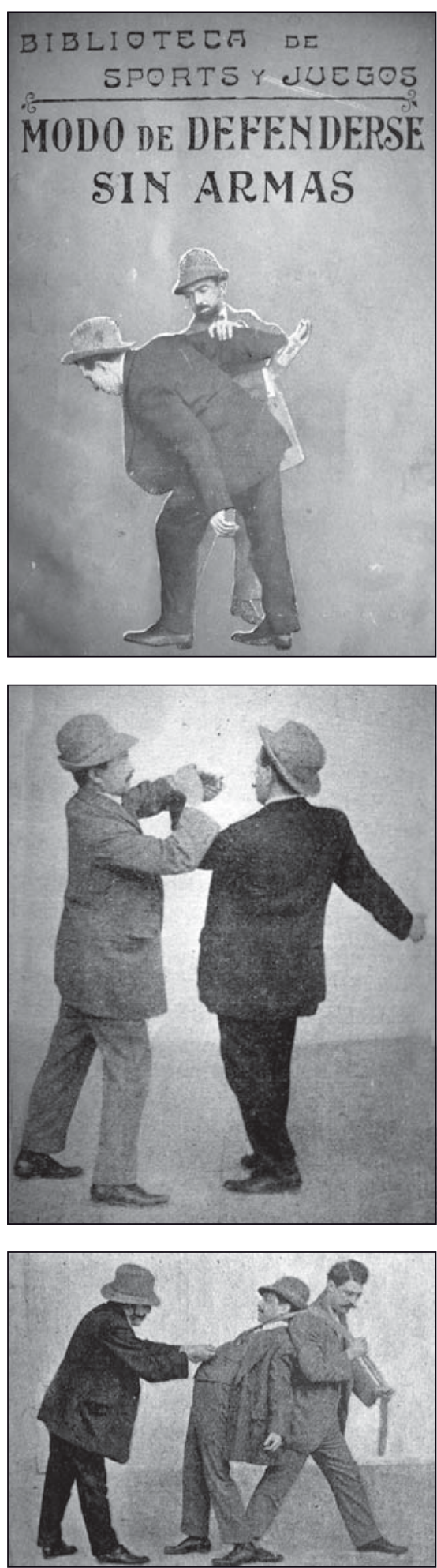

Portada y algunas ilustraciones del libro La defensa en la calle. Cómo hacerse inexpugnable. La última fotografía ilustra el famoso Coup de le Père François (Golpe del padre Francisco), supuestamente uno de los favoritos de los "apaches". 
Llaverías y Rovirosa, Amadeo (1910). Catálogo de la biblioteca del Gimnasio Colón. [Barcelona]: [Antonio Palau].

Montespín, René de [1910?]. Los Sports de moda. Foot-ball. Water-polo. JiuJitsu. Barcelona: Ibero-Americana.

Museo Pedagógico Nacional (1915). Bibliografía y material de enseñanza. Educación física. Higiene escolar. Madrid: Rojas.

Nelson, Randy F. with Whitaker, Katherine C. (1988). The Martial Arts Index: An Annotated Bibliography. New York \& London: Garland Publishing Incorporated.

Palau y Dulcet, Antonio (1935). Catálogo de la biblioteca del Gimnasio Colón formado por Amadeo Llaverías y Rovirosa. Barcelona: Antonio Palau.

Palau y Dulcet, Antonio (1948-49). Manual del Librero Hispano-Americano. Barcelona: Librería Anticuaria de Antonio Palau.

Péchard, Charles [1906]. Le Jiu-Jitsu pratique. Méthode de defense et d'ataque enseignant 100 moyens d'arrêter, inmobiliser, terrasser, conduire ou emporter un malfaiteur, même armé. París : Jules Rueff.

Ré-Nié, Professeur (1906). Les Secrets de Jiu-Jitsu. París: Librairie Paul Paclot.

Rit-Jou-Ku [191?]. Modo de defenderse sin armas. La defensa en la calle. Cómo hacerse inexpugnable. B. Bauza: Barcelona.

Rodao, Florentino (2002). Franco y el imperio japonés. Barcelona: Plaza Janés.

S.a. [1908]. Breve tratado de jiu-jitsu. Principales llaves de defensa que usan los más renombrados campeones de la lucha japonesa. Barcelona: Imprenta viuda de J. Cunill.

S.a. (1909). Los Secretos del "Jiu-Jitsu". Madrid: s.n. Obra publicada en la Revista La Semana Ilustrada, Madrid, nos 89, 90, 91, 92, 93, 94 y 95, 9, 16, 23, 30 de enero, 6, 13, y 20 de febrero de 1909 respectivamente.

Saimbraum (seud. de Bardina, Joan) (1914). Modos de defenderse en la calle sin armas. Lecciones prácticas de boxeo, jiu-jitsu, lucha grecoromana, etc. Barcelona: Talleres gráficos de la Sociedad General de Publicaciones.

Smith, Robert W. (1961). A Bibliography of Judo. Rutland \& Tokio: Charles E. Tuttle Company.

Sue-Hee, Kim Lee (1988). La presencia del Arte de Extremo Oriente en España a fines del siglo XIX y principios del siglo XX. Madrid: Editorial de la Universidad Complutense.

Surier, Albert [1905]. "Jiu-Jitsu". En P. Moreau y G. Voulquin G. (Dirs.) Les Sports modernes illustrés, París: Larousse, pp. 193-196.

Toschi, Livio (1993). "La Marina Militare italiana in Cina (1906) e la diffusione della 'lotta giapponese' in Italia”. Rassegna Storica Del Risorgimento, 80 (3), 344-365.

Uequín, Juan Carlos (2005). Historia del judo argentino. Tomo I. Buenos Aires: Kier.

Urbina Gaitán, Chester (2006, junio). "Origenes del deporte moderno en El Salvador (1895-1921)”. Lecturas: EF y Deportes. Revista digital, 97. Accesible en http://www.efdeportes.com/efd97/salvador.htm. [Consulta 01/11/2006].

Uyenishi, Sada Kazu (Raku) [1905]. The Text-book of Ju-Jutsu as Practised in Japan. London: Athletic Publications Ltd.

Vila, Óscar (1918). Conviene la gimnasia al sexo débil?. Rosario: Tipografía Bacino.

Vila, Óscar (1918). Gimnasia Respiratoria. [Rosario]: s.n. 
Vila, Óscar (1918). Ataxia locomotriz. Reeducación gimnástica de los músculos afectados. s.l.: s.n.

Vila, Óscar (1918). Programas de Ejercicios Físicos para las Escuelas Primarias. Rosario: Tipografía Bacino.

Vila, Óscar (1914). Lecciones prácticas de jiu-jitsu. Rosario: E.A. Larrazábal.

\section{Notas}

1 Supuestamente basado en la obra de los mismos autores Jiu Jitsu: The Effective Japanese Mode of Self Defense. American Sports Publishing: New York. No hemos querido comentar esta obra al no tener constancia de que la edición en español respetase fielmente el original.

2 La obra no está fechada. Tomamos este dato de Brousse (2000: 453). La edición española conocería diversas reediciones, en 1909, 1911 y 1923 . En 1976 Editores Mexicanos reeditaría la obra bajo el título Método efectivo de defensa personal. Ataques y quites. 100 lances de jiu-jitsu, donde se señala que la traducción es de Ceferino Domínguez.

${ }^{3}$ La edición francesa de la obra de Hancock e Higashi se publicaría en 1908 bajo el título Traité complet de Jiu-Jitsu. Méthode Kano.

${ }^{4}$ Este apartado está basado en el anterior trabajo del autor "Estudio de la obra tratado de Ju Jutsu y sus secretos, primer libro editado en España sobre las artes marciales".

5 Fecha asignada a la obra según el Catalogue collectif de France (http://ccfr. bnf.fr/rnbcd_visu/acc1.htm).

6 Fecha atribuida por Rufino Blanco (1927: I, 415). La fecha posiblemente no sea anterior ya que Llaverías no refiere la obra en su Catálogo de la biblioteca del Gimnasio Colón (1910).

7 Rufino Blanco (1927: I, 786) en su Bibliografía General de la Educación Física cita una edición de la obra publicada en París sobre 1900 (1900?). No obstante no tenemos ninguna otra referencia a este supuesto trabajo que no es referido por Brousse (2000) ni se localiza en el Catalogue collectif de France (http://ccfr.bnf.fr/rnbcd_visu/acc1.htm).

8 Véase la página web del Centre D’Estudis Joan Bardina (http://www. pangea.org/ jbardina/index.htm), y concretamente el catálogo de sus obras (http://www.pangea.org/ jbardina/brpces09.htm).

9 Tomamos esta referencia de la obra de Antonio Palau y Dulcet Catálogo de la biblioteca del Gimnasio Colón formado por Amadeo Llaverías y Rovirosa, en el que se añaden un buen número de referencias al catálogo original realizado por Amadeo Llaverías en 1910. Hemos podido consultar otra edición posterior de la obra, también sin datar, de 113 páginas.

${ }^{10}$ La cita original de Berger es "Lo que contaba no era la cultura de Japón, ni incluso la historia objetiva del arte japonés, sino simple y puramente aquellas cosas que los artistas de París querían ver y eran capaces de ver". 